This item was submitted to Loughborough's Research Repository by the author.

Items in Figshare are protected by copyright, with all rights reserved, unless otherwise indicated.

\title{
Inefficiency predictions in a hypoid gear pair through tribodynamics analysis
}

PLEASE CITE THE PUBLISHED VERSION

https://doi.org/10.1016/j.triboint.2017.11.035

PUBLISHER

(c) Elsevier

VERSION

AM (Accepted Manuscript)

\section{PUBLISHER STATEMENT}

This work is made available according to the conditions of the Creative Commons Attribution-NonCommercialNoDerivatives 4.0 International (CC BY-NC-ND 4.0) licence. Full details of this licence are available at: https://creativecommons.org/licenses/by-nc-nd/4.0/

\section{LICENCE}

CC BY-NC-ND 4.0

\section{REPOSITORY RECORD}

Paouris, Leonidas I., Ramin Rahmani, Stephanos Theodossiades, Homer Rahnejat, Gregory Hunt, and William Barton. 2017. "Inefficiency Predictions in a Hypoid Gear Pair Through Tribodynamics Analysis". Loughborough University. https://hdl.handle.net/2134/27584. 


\title{
Inefficiency Predictions in a Hypoid Gear Pair through Tribodynamics Analysis
}

\author{
L. Paouris ${ }^{1}$, R. Rahmani ${ }^{1}$, S. Theodossiades ${ }^{1}$, H. Rahnejat ${ }^{1}$, G. Hunt ${ }^{2}$, W. Barton ${ }^{2}$ \\ ${ }^{1}$ Wolfson School of Mechanical and Manufacturing Engineering, Loughborough University, \\ Loughborough, Leicestershire, UK \\ ${ }^{2}$ Applied Sciences Department, Lubrizol Limited., Hazelwood, Derbyshire, UK
}

\begin{abstract}
A tribo-dynamics model, predicting the conjunctional inefficiency and dynamic response of automotive hypoid gear pairs is presented. A dynamics model is coupled with an analytical friction model (viscous and boundary). The temperature rise at the centre of the conjunction is accounted for through use of thermal network model and Time Temperature Superposition (TTS) method, as well as the time varying geometry of the meshing gear teeth. Newtonian and non-Newtonian lubricant shear behaviour are both considered Surface topography measurements of a run-in pinions are obtained. Inefficiency calculations are performed for typical automotive drive cycle snapshots. Precisely measured lubricant shear characterstics for lubricants different blended viscosity modifiers and evolving surface topography are used in the study of transmission inefficiency. The integrated thermal-tribodynamic analysis is shown to distinguish between different viscosity modifier types, an approach not hitherto reported in literature.
\end{abstract}

Keywords: Mechanical transmission inefficiency; Hypoid Gears; Lubricant rheology; Viscosity Modifiers

\section{Introduction}

The continuing demand for decreasing road vehicle emissions and stringent regulations imposed on both the OEMs as well as their suppliers has strengthened the demand towards improving the overall fuel efficiency of modern automotive transmission systems. By reducing the power losses associated with friction in such systems, it is possible to reduce the energy losses as well as the resulting vehicular emissions. A component of particular interest, with regards to power train friction is the hypoid gear pair, which is part of the differential of the automotive drivetrain system. The significant sliding at the gear teeth contacts, combined with the increased loading can contribute towards frictional power losses [1]. Hence, the development of axle lubricants with improved tribological performance can lead to improved fuel efficiency. To better understand the contribution of the axle lubricant rheology to the conjunction efficiency of the hypoid gear pair, it is necessary to develop an efficient numerical analysis methodology. In addition, although experimental studies focusing on the inefficiency of the rear axles exist in the literature (i.e., [2-5]), the analysis of the problem from a theoretical standpoint can offer a better fundamental insight into the physical phenomena involved. 
With regards to the past literature related to the lubrication of hypoid gear pairs, the study by Simon [6] in the early 1980s can be considered as one of the first attempts in addressing the problem. Quasi-static conditions were assumed, while the kinematics and the elastostatics of the complex teeth conjunction are described through Tooth Contact Analysis TCA. Although the tooth loads considered were low and thus not representative of realistic vehicular operating conditions, this study set the basis of the methodology to be used when examining the lubrication performance of such components. Later, $\mathrm{Xu}$ et al. [7,8] and Kolivand et al. [9] predicted the conjunctional efficiency of highly loaded hypoid gear pairs under quasi-static conditions using numerical models. The flank friction was calculated analytically, using a set of empirical/experimental relationships and numerically through solution of line contact Newtonian elastohydrodynamic (EHD) problem. Mohammadpour et al. [10] extended the solution of the EHD problem in hypoid gears by considering an elliptical contact footprint. The effect of the angle flow component of the lubricant entraining velocity was also accounted for. However, the lubricant was considered to undergo Newtonian shear. Consequently, the shear thinning action was not observed. Later, Mohammadpour et al. [11] extended their analysis to account for the non-Newtonian response of the axle lubricant. The impact of the dynamic response of the hypoid gear pair on the conjunctional efficiency was examined by Karagiannis et al. [12] following an analytical approach for predicting flank friction. Mohammadpour et al. [13] extended the aforementioned approach to account for the effect of lateral vibrations of the supporting shafts, which are due to the compliance of their supporting bearings.

The results in [13] have shown the potenial for tribodynamic analysis to predict the transmission system performance in a realistic emission cycle such as the NEDC. This approach provides a further opportunity for a suitably refined tribodynamic model to ascertain the effect of lubricant chemistry (additves) on transmission system performance in specified manoeuvres such as various drive cycles. For such an undertaking a detailed rheological model should be created to account for lubricant behaviour under a wide range of loading and shear conditions, including its rheological response at high pressure and shear, linked to lubricant chemistry. The work in [13] does not include such an approach. It uses an an overall empirical lubricant characteristics subject to non-Newtonian shear. The current study, on the other hand includes detailed measured lubricant behaviour with the inclusion of different viscosity modifying species subject to a wide range of loading and shear as described later. This is one of the main contributions of this study.

When analysing gear transmission systems, transient dynamics is required to address system non-linearities and to ascertain the extent of system stability and attainment of desired periodic motions. For example, when utilising a transient dynamic model, it is possible to capture the effect of resonance on the gear pair performance. In addition, this allows accurate prediction of dynamic loads of contacting teeth pairs. The inertial dynamics are normally under-estimated with quasi-static analyses. Therefore, inertial dynamics is required for evaluation of both transmission efficiency and NVH assessment. Thus, in the current study, a 4 DoF gear dynamics model, along with realistic TCA data is employed to account for the impact of the dynamic response of the hypoid gear pair on its conjunctional inefficiency. More importantly, realistic rheological data describing the high pressure and high shear response of fully blended axle lubricants are employed. The thermal effects due to the presence of flank friction are also accounted for by using a time-efficient analytical approach, yielding more realistic predictions of conjunctional inefficiency. The methodology presented in this paper distinguishes between the performance of fluids containing different types of viscosity modifiers (VM). 
In the currently expounded tribodynamics model, an appropriate analytical thermal network partitioning model for the generated heat in the contact between the conjunction surfaces is used. The lubricant shear heating effect is also taken into account through Time Temperature Superposition (TTS) method with the use of specifically measured data for each lubricant, based on its TTS coefficient. In addition, in the current study, the contribution due to boundary friction is obtained, based on incorporating the measured surface roughness data for the contacting gear pair, including the combined average radius of curvature of asperity tips, composite RMS roughness values and the combined asperity peak density values. This approach improves the predictions of real system behaviour.

It is shown that the developed analytical approach in the form of a thermal tribodynamics model establishes a link between the rheological properties of transmission fluid's additives in the form of various viscosity modifiers and gear dynamic performance, measured through transmission efficiency. In particular, the model is shown to be sufficiently sensitive to the effect of various viscosity modifiers.

\section{Problem Formulation}

A torsional gear dynamics solver is developed to predict the dynamic response of the gear pair under a wide range of input torque data. The conjunctional friction is considered in the equations of motion. Employing a gear dynamics model into the analysis of the conjunctional friction enables the identification of regions of interest during the operation of the gear pair, such as the first primary resonance. When operating at or near these regions, tooth separation occurs, leading to changes in the frictional losses with respect to an equivalent quasi-static analysis $[12,14]$. An analytical approach is employed to calculate the magnitude of friction at each time step of simulation. The viscous and boundary components of friction between the meshing gear teeth pairs are taken into account in the friction model. The temperature rise at the central region of the EHD conjunction is accounted for by employing an analytical thermal model. The calculation of the component of boundary friction is performed, using the Greenwood-Tripp model [15]. The Greenwood-Tripp parameters describing the roughness features of the gear teeth surfaces are determined by utilising a $3 \mathrm{D}$ Alicona ${ }^{\mathrm{TM}}$ optical interferometer and following the procedure recommended by Arcoumanis et al. [16]. A run-in pinion tooth was employed to conduct the surface topography measurements. The instantaneous contact geometry and the instantaneous meshing stiffness are determined through use of TCA data, available in published literature [14] to represent a realistic set of hypoid gear pair design.

The method of study is based on the decomposition of the problem into two separate models including a 4-DoF torsional gear dynamics model and a friction model. Each model is solved separately with the output of the other forming its input, iterating to a single solution. This is a co-simulation approach. The methodologies employed for each model are described in the following sections.

\subsection{Gear dynamics model}

A 4-DoF torsional gear dynamics model (Figure 1) is used to predict the dynamic response of the hypoid gear pair. The degrees of freedom considered are the angular displacements of the pinion shaft, the pinion wheel, the gear wheel and the gear shaft. An 
additional integration in time domain is performed to calculate the Dynamic Transmission Error (DTE) through use of its time history of response [17]. The equations of motion for the 4-DoF lumped parameter torsional gear dynamics model are expressed as:

$$
\begin{aligned}
& \ddot{\varphi}_{\mathrm{s}}=\frac{1}{\mathrm{I}_{\mathrm{s}}}\left[-\mathrm{k}_{\mathrm{t} 1}\left(\varphi_{\mathrm{s}}-\varphi_{\mathrm{p}}\right)-\mathrm{c}_{\mathrm{t} 1}\left(\dot{\varphi}_{\mathrm{s}}-\dot{\varphi}_{\mathrm{p}}\right)+\mathrm{T}_{\mathrm{s}}\right] \\
& \ddot{\varphi}_{\mathrm{p}}=\frac{1}{\mathrm{I}_{\mathrm{p}}}\left[-\mathrm{R}_{\mathrm{p}}\left(\mathrm{k}_{\mathrm{m}} \mathrm{f}+\mathrm{c} \dot{\mathrm{x}}\right)+\mathrm{k}_{\mathrm{t} 1}\left(\varphi_{\mathrm{s}}-\varphi_{\mathrm{p}}\right)+\mathrm{c}_{\mathrm{t} 1}\left(\dot{\varphi}_{\mathrm{s}}-\dot{\varphi}_{\mathrm{p}}\right)+\mathrm{T}_{\mathrm{fr}, \mathrm{p}}\right] \\
& \ddot{\varphi}_{\mathrm{g}}=\frac{1}{\mathrm{I}_{\mathrm{g}}}\left[\mathrm{R}_{\mathrm{g}}\left(\mathrm{k}_{\mathrm{m}} \mathrm{f}+\mathrm{cx}\right)-\mathrm{k}_{\mathrm{t} 2}\left(\varphi_{\mathrm{g}}-\varphi_{\mathrm{w}}\right)-\mathrm{c}_{\mathrm{t} 2}\left(\dot{\varphi}_{\mathrm{g}}-\dot{\varphi}_{\mathrm{w}}\right)+\mathrm{T}_{\mathrm{fr}, \mathrm{g}}\right] \\
& \ddot{\varphi}_{\mathrm{w}}=\frac{1}{\mathrm{I}_{\mathrm{w}}}\left[\mathrm{k}_{\mathrm{t} 2}\left(\varphi_{\mathrm{g}}-\varphi_{\mathrm{w}}\right)+\mathrm{c}_{\mathrm{t} 2}\left(\dot{\varphi}_{\mathrm{g}}-\dot{\varphi}_{\mathrm{w}}\right)-\mathrm{T}_{\mathrm{w}}\right]
\end{aligned}
$$

Figure 1 provides a schematic diagram of the torsional gear dynamics model employed in the present study. As shown, the torsional elasticity of the supporting shafts of the pinion and the ring gear, as well as their corresponding torsional damping are included. The arrow at the spring represents the meshing stiffness, $\mathrm{k}_{\mathrm{m}}$, which denotes the non-linearity of the gear meshing contacts.

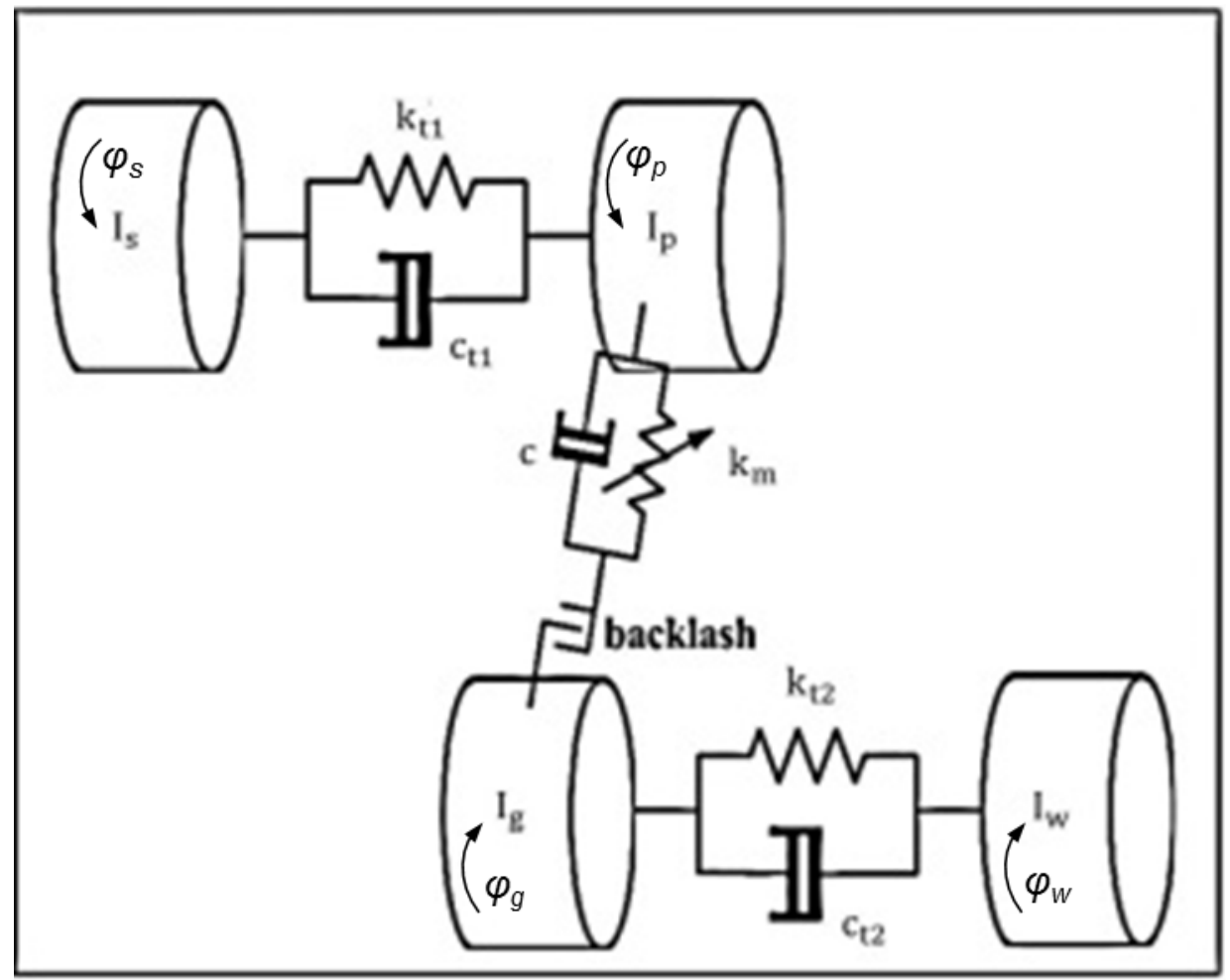

Figure 1: The 4-DoF torsional gear dynamics model

In equations $(1-4)$, the backlash function, $\mathrm{f}$, the dynamic transmission error, $\mathrm{x}$, and the resistive torque at the gear shaft, $\mathrm{T}_{\mathrm{w}}$, are calculated as: 


$$
\begin{aligned}
& f=\left\{\begin{array}{cl}
x-b & \text { when } x \geq b \\
0 & \text { when }-b<x<b \\
x+b & \text { when } x \leq-b
\end{array}\right. \\
& \mathrm{x}(\mathrm{t})=\int\left[\mathrm{R}_{\mathrm{p}}(\mathrm{t}) \dot{\varphi}_{\mathrm{p}}-\mathrm{R}_{\mathrm{g}}(\mathrm{t}) \dot{\varphi}_{\mathrm{g}}\right] \mathrm{dt}-\mathrm{e}(\mathrm{t}) \\
& \mathrm{T}_{\mathrm{w}}(\mathrm{t})=\mathrm{r}_{\mathrm{w}}\left\{\mathrm{m}_{\mathrm{v}} \mathrm{gf}_{\mathrm{r}} \cos (\mathrm{a})+\mathrm{m}_{\mathrm{v}} \mathrm{g} \sin (\mathrm{a})+\mathrm{c}_{\mathrm{a}} \mathrm{A}_{\mathrm{f}} \frac{\rho_{\mathrm{air}}}{2}\left[\mathrm{u}_{\mathrm{v}}(\mathrm{t})\right]^{2}\right\}
\end{aligned}
$$

The calculation of the resistive torque on the ring gear shaft (equation 7) takes into account the rolling resistance between the tyre and the road, the resistance due to any road inclination (i.e. grading) and the aerodynamic drag [18]. Finally, instantaneous values (during the meshing cycle) of the contact radii of the pinion and the gear, the meshing stiffness and the Static Transmission Error (STE) are calculated using [19]:

$$
\begin{aligned}
& \mathrm{R}_{\mathrm{g}}=\mathrm{R}_{\mathrm{g} 0}+\sum_{\mathrm{i}} \mathrm{R}_{\mathrm{gsi}} \sin \left(\mathrm{iN}_{\mathrm{g}} \varphi_{\mathrm{g}}\right)+\sum_{\mathrm{i}} \mathrm{R}_{\mathrm{gci}} \cos \left(\mathrm{iN}_{\mathrm{g}} \varphi_{\mathrm{g}}\right) \\
& \mathrm{R}_{\mathrm{p}}=\mathrm{R}_{\mathrm{p} 0}+\sum_{\mathrm{i}} \mathrm{R}_{\mathrm{psi}} \sin \left(\mathrm{iN}_{\mathrm{p}} \varphi_{\mathrm{p}}\right)+\sum_{\mathrm{i}} \mathrm{R}_{\mathrm{pci}} \cos \left(\mathrm{iN}_{\mathrm{p}} \varphi_{\mathrm{p}}\right) \\
& \mathrm{k}_{\mathrm{m}}=\mathrm{k}_{\mathrm{m} 0}+\sum_{\mathrm{i}} \mathrm{k}_{\mathrm{msi}} \sin \left(\mathrm{iN}_{\mathrm{p}} \varphi_{\mathrm{p}}\right)+\sum_{\mathrm{i}} \mathrm{k}_{\mathrm{mci}} \cos \left(\mathrm{iN}_{\mathrm{p}} \varphi_{\mathrm{p}}\right) \\
& \mathrm{e}=\mathrm{e}_{0}+\sum_{\mathrm{i}} \mathrm{e}_{\mathrm{si}} \sin \left(\mathrm{iN}_{\mathrm{p}} \varphi_{\mathrm{p}}\right)+\sum_{\mathrm{i}} \mathrm{e}_{\mathrm{ci}} \cos \left(\mathrm{iN}_{\mathrm{p}} \varphi_{\mathrm{p}}\right)
\end{aligned}
$$

Equations $(8-11)$ are expanded up to the $8^{\text {th }}$ term since no significant change in their variation is observed when higher order terms are included. The values of the Fourier coefficients are the same as those used by Mohammadpour et al. [20] and correspond to a hypoid gear pair with the characteristics displayed in Table 1.

Table 1: Geometric features of the studied hypoid gear pair

\begin{tabular}{lll}
\hline Parameter (unit) & Pinion & Gear \\
\hline Teeth Number $(-)$ & 13 & 36 \\
\hline Face Width $(\mathrm{mm})$ & 33.851 & 29.999 \\
\hline Face Angle $\left(^{\circ}\right)$ & 29.056 & 59.653 \\
\hline Pitch Angle $\left(^{\circ}\right)$ & 29.056 & 59.653 \\
\hline Root Angle $\left(^{\circ}\right)$ & 29.056 & 59.653 \\
\hline Spiral Angle $\left(^{\circ}\right)$ & 45.989 & 27.601 \\
\hline Pitch Apex $(\mathrm{mm})$ & -9.085 & 8.987 \\
\hline Face Apex $(\mathrm{mm})$ & 1.368 & 10.948 \\
\hline Outer Cone Distance $(\mathrm{mm})$ & 83.084 & 95.598 \\
\hline Offset (mm) & 24.0 & 24.0 \\
\hline Sense (hand) & Right & Left \\
\hline
\end{tabular}

\subsection{Friction model}

To reduce the computational burden, the coefficient of viscous friction is calculated using an analytical method. The model employed is explained in this section. 
It is known that the film thickness in hypoid gear pair conjunctions can be adequately described by the magnitude of the central lubricant film thickness [21]. The contacting surfaces of the meshing pairs are assumed to be smooth. Therefore, the effect of micro-EHL which can cause pressure perturbations in the contact is ignored in the current analysis. In practice there would be some micro-EHL effect, depending on the roughness of meshing surfaces as shown in [22]. Assumption of a Hertzian pressure distribution is also reasonable because most meshing teeth pair contacts are subject to various degrees of starvation. However, the effect of surface roughness on (boundary) friction has been included in the current analysis through use of well-establsihed asperity contact models (section 2.5). Therefore, using the Chittenden-Dowson relationship [23] the central film thickness can be calculated as:

$$
\mathrm{h}_{\text {cen }}=4.31 \mathrm{R}_{\mathrm{e}} \mathrm{U}_{\mathrm{e}}^{0.68} \mathrm{G}^{0.49} \mathrm{~W}_{\mathrm{e}}^{-0.073}\left[1-\mathrm{e}^{-1.23\left(\mathrm{R}_{\mathrm{s}} / \mathrm{R}_{\mathrm{e}}\right)^{2 / 3}}\right]
$$

The dimensionless parameters can be calculated according to [23]:

$$
\mathrm{U}_{\mathrm{e}}=\frac{\eta_{0}\left(\mathrm{~T}_{\mathrm{in}}\right) \mathrm{U}_{\mathrm{eff}}}{\mathrm{E}^{\prime} \mathrm{R}_{\mathrm{e}}}, \quad \mathrm{G}=\alpha^{*}\left(\mathrm{~T}_{\mathrm{in}}\right) \mathrm{E}^{\prime}, \quad \mathrm{W}_{\mathrm{e}}=\frac{\mathrm{W}}{\mathrm{E}^{\prime} \mathrm{R}_{\mathrm{e}}{ }^{2}}, \quad \text { where, } \mathrm{E}^{\prime}=\frac{\mathrm{E}}{1-\mathrm{v}^{2}}
$$

where, $\mathrm{W}$ is the portion of load carried by the EHL film.

In the above relationships, the low shear dynamic viscosity, $\eta_{0}$, and the pressure viscosity coefficient, $\alpha^{*}$, are estimated at the inlet temperature, $\mathrm{T}_{\mathrm{in}}$, of the EHD conjunction instead of the bulk (or oil sump) temperature, $\mathrm{T}_{\mathrm{b}}$. This is to account for heat conduction from the gear teeth at the inlet meniscus. To evaluate the temperature of the gear teeth when engaging, a heat transfer model should be developed. Since this is considered to be a trivial exercise, for the purposes of the present investigation, the inlet temperature rise is estimated by the following rule of thumb according to Olver [24]:

$$
\Delta \mathrm{T}_{\text {in }}=\mathrm{T}_{\text {in }}-\mathrm{T}_{\mathrm{b}}=20^{\circ} \mathrm{C}
$$

A more thorough investigation should include the effect of inlet shear heating and the associated temperature rise, particulalry under starved conditions, similar to that reported in [25].

In addition, the viscosity used for the calculation of central film thickness in equation (12) corresponds to the value obtained at ambient (atmospheric) pressure conditions. Furthermore, the equivalent contact radii of curvature in equations (12-13) can be calculated according to Chittenden et al. [23]:

$$
\begin{gathered}
\frac{1}{R_{e}}=\frac{\cos ^{2}(\theta)}{R_{z x}}+\frac{\sin ^{2}(\theta)}{R_{z y}} \\
\frac{1}{R_{s}}=\frac{\sin ^{2}(\theta)}{R_{z x}}+\frac{\cos ^{2}(\theta)}{R_{z y}}
\end{gathered}
$$

where $\theta$ corresponds to the angle between the velocity vector of lubricant entering into the conjunction and the semi-minor axis of the elliptical contact footprint. Hence, it can be calculated as $\theta=\tan ^{-1}(\mathrm{~V} / \mathrm{U})$. The local contact radii of curvature, $\mathrm{R}_{\mathrm{zx}}$ and $\mathrm{R}_{\mathrm{zy}}$, are determined at each time step throughout the meshing cycle using the TCA data. Finally, the effective entraining velocity used in the central film thickness equation (equation 12) can be determined as [23]:

$$
\mathrm{U}_{\mathrm{eff}}=\mathrm{U} \cos (\theta)+\mathrm{V} \sin (\theta)
$$


where, $\mathrm{U}=\left(\mathrm{u}_{\mathrm{s}, \mathrm{p}}+\mathrm{u}_{\mathrm{s}, \mathrm{g}}\right) / 2$ and $\mathrm{V}=\left(\mathrm{v}_{\mathrm{s}, \mathrm{p}}+\mathrm{v}_{\mathrm{s}, \mathrm{g}}\right) / 2$ are the lubricant velocities along the entraining and the side leakage directions, respectively. The individual tooth surface velocities, $u_{s, p}, u_{s, g}, v_{s, p}$ and $v_{s, g}$ are evaluated using the gear dynamics model, which is integrated with the corresponding TCA data at each simulation time step.

Once the central film thickness is obtained, the lubricant shear rate at the centre of the EHD conjunction can be calculated. To proceed with the calculations, it is assumed that the shear rate at the centre is only due to the Couette flow, which is widely accepted in the relevant literature, particularly when analytical models are employed [26]. Hence, the lubricant shear rate can be obtained as:

$$
\dot{\gamma}=\frac{\left|\overrightarrow{\mathrm{V}}_{\mathrm{s}}\right|}{\mathrm{h}_{\mathrm{cen}}}
$$

where, $\mathrm{V}_{\mathrm{S}}$ corresponds to the total sliding velocity in the EHD conjunction, accounting for the sliding velocity components in both the entraining and the side leakage directions. To calculate $\mathrm{V}_{\mathrm{s}}$, first the $x$ and $y$ components of velocities of each surface are predicted. Then, the resultant sliding velocity in each direction is found. Finally, the magnitude of $V_{s}$ is computed through the vector sum of these sliding velocity components.

The viscous shear stress in the conjunction is a function of pressure distribution, which needs to be determined a priori using the Hertzian model. This is a sufficiently good assumption for highly loaded hypoid gear pair conjunctions [26]. Consequently, the local pressure distribution becomes [27]:

$$
p(x, y)=\frac{3 W}{2 \pi a_{c} b_{c}} \sqrt{1-\left(x / b_{c}\right)^{2}-\left(y / a_{c}\right)^{2}}
$$

The semi-major and the semi-minor axes of the contact footprint are given by [28]:

$$
a_{c}=\left(\frac{6(\bar{k} \cdot \bar{\varepsilon})^{2} W R_{e}}{\pi E^{\prime}}\right)^{1 / 3} \quad, b_{c}=\left(\frac{6 \bar{\varepsilon} W R_{e}}{\pi \bar{k} E^{\prime}}\right)^{1 / 3}
$$

where $R_{e}=\left(R_{z x} R_{z y}\right) /\left(R_{z x}+R_{z y}\right)$ corresponds to the equivalent radius of curvature of the conjunction, whereas $\overline{\mathrm{k}}$ and $\bar{\varepsilon}$ are the ellipticity parameter and the simplified elliptical integral respectively, which can be calculated as [28]:

$$
\begin{aligned}
& \overline{\mathrm{k}}=1.0339\left(\mathrm{R}_{\mathrm{zy}} / \mathrm{R}_{\mathrm{zx}}\right)^{0.636} \\
& \bar{\varepsilon}=1.0003+0.5968\left(\mathrm{R}_{\mathrm{zy}} / \mathrm{R}_{\mathrm{zx}}\right)
\end{aligned}
$$

Since the pressure is known, the local viscous shear stress can be calculated as:

$$
\tau=\frac{\eta\left(\mathrm{p}, \overline{\mathrm{T}}_{\mathrm{c}}\right)}{\mathrm{F}\left(\dot{\gamma}, \overline{\mathrm{T}}_{\mathrm{c}}\right)} \dot{\gamma}
$$

where $\mathrm{F}$ is the non-Newtonian (shear-thinning) function. In equation (23) the low shear dynamic viscosity, $\eta$, is calculated at any pressure, based on the average temperature at the centre of the conjunction, $\overline{\mathrm{T}}_{\mathrm{c}}$, which is calculated according to the methodology presented in section 2.4. The effect of the limiting shear stress is also accounted for by restricting the shear stress to a value less than or equal to $\tau_{\mathrm{L}}$, which is calculated according to Hoglund and Jacobson [29] as: $\tau_{\mathrm{L}}=\tau_{\mathrm{L}, 0}+\gamma_{\mathrm{L}} \mathrm{p}$, where $\gamma_{\mathrm{L}}=0.029$ and $\tau_{\mathrm{L}, 0}=4 \mathrm{MPa}$ as recommended for PAO lubricants at $40{ }^{\circ} \mathrm{C}$ [29]. In the absence of specific data for the variation of the limiting 
shear stress with temperature, particularly at high pressures, the limiting shear stress is assumed to be independent of temperature in the current analysis. The temperature and pressure variation of the low shear dynamic viscosity are also discussed in the following sections. In addition, the non-Newtonian (shear thinning) function, F, can be calculated according to the Havriliak-Negami non-Newtonian model [30] as:

$$
\mathrm{F}\left(\dot{\gamma}, \overline{\mathrm{T}}_{\mathrm{c}}\right)=\left\{1+\left[\lambda \mathrm{a}_{\mathrm{TTS}}\left(\overline{\mathrm{T}}_{\mathrm{c}}\right) \dot{\gamma}\right]^{\alpha_{\mathrm{HN}}}\right\}^{\beta_{\mathrm{HN}}}
$$

where $\lambda$ corresponds to the relaxation time of the polymer in the solution and $\alpha_{\mathrm{HN}}$ and $\beta_{\mathrm{HN}}$ are the Havriliak-Negami coefficients. The Time Temperature Superposition (TTS) shifting factor, $\mathrm{a}_{\text {TTS }}$, is a function of temperature [31]. The TTS accounts for the variations of the employed parameters with temperature. For the current study, the reference temperature used to calculate the aforementioned coefficients is $\mathrm{T}_{\text {ref }}=70^{\circ} \mathrm{C}$. The TTS coefficient, $\mathrm{a}_{\mathrm{TTS}}$, can be calculated as [32]:

$$
\mathrm{a}_{\mathrm{TTS}}(\mathrm{T})=\frac{\eta(\mathrm{T})}{\eta\left(\mathrm{T}_{\mathrm{ref}}\right)} \cdot \frac{\mathrm{T}_{\mathrm{ref}}}{\mathrm{T}} \cdot \frac{\rho\left(\mathrm{T}_{\mathrm{ref}}\right)}{\rho(\mathrm{T})}
$$

where, the temperature variation of the density of the lubricants used is provided by the lubricant manufacturer through the following relationship:

$$
\rho(\mathrm{T})=-0.6323 \mathrm{~T}+1016.1
$$

Once the average viscous shear stress, $\bar{\tau}$, is calculated by averaging the local shear stress calculated from equation (23), the viscous friction is obtained as:

$$
\mathrm{F}_{\mathrm{v}}=\left(\mathrm{A}_{\mathrm{EHL}}-\mathrm{A}_{\mathrm{asp}}\right) \bar{\tau}
$$

where, $A_{\text {asp }}$ is the total area of asperity interactions, which is determined according to the methodology presented in section 2.5 . The procedure to calculate the boundary friction, $\mathrm{F}_{\mathrm{b}}$, is also described in the same section.

Thus, the total flank friction force can be calculated as:

$$
\mathrm{F}_{\mathrm{fr}}=\mathrm{F}_{\mathrm{v}}+\mathrm{F}_{\mathrm{b}}
$$

In addition, the total frictional torque can be found as:

$$
\mathrm{T}_{\mathrm{fr}, \mathrm{i}}=\sum_{\mathrm{k}=1}^{3} \mathrm{~T}_{\mathrm{fr}, \mathrm{i}}^{\mathrm{k}}=\sum_{\mathrm{k}=1}^{3} \mathrm{r}_{\mathrm{fr}, \mathrm{i}} \mathrm{F}_{\mathrm{fr}}^{\mathrm{k}}
$$

where $\mathrm{i}=\mathrm{p}$ for the pinion and $\mathrm{i}=\mathrm{g}$ for the ring gear, $\mathrm{F}_{\mathrm{fr}}^{\mathrm{k}}$ represents the total flank friction acting on the $\mathrm{k}^{\text {th }}$ flank of the pinion/gear member and $\mathrm{r}_{\mathrm{fr}, \mathrm{i}}$ represents the moment arm of the friction about the shaft of either the pinion or the ring gear. In the equation above, it is assumed that a maximum of 3 flanks are in simultaneous contact. This is in line with the findings of existing studies on the elasto-static contact of highly loaded hypoid gear pairs $[12,14]$.

The percentage inefficiency is calculated based on the RMS of the instantaneous conjunctional inefficiency for 50 meshing cycles under steady state conditions. The instantaneous conjunctional inefficiency is calculated as:

$$
\text { In }=100 \frac{\sum_{\mathrm{k}=1}^{3}\left|\mathrm{~V}_{\mathrm{s}}^{\mathrm{k}} \mathrm{F}_{\mathrm{fr}}^{\mathrm{k}}\right|}{\mathrm{T}_{\mathrm{s}} \dot{\varphi}_{\mathrm{s}}} \%
$$


In equation (30), the numerator corresponds to the instantaneous conjunctional power losses of the flanks, whereas the denominator represents the instantaneous supplied power.

\subsection{Lubricant properties}

The lubricants used were polyalphaolefin (PAO) base of SAE 75W90 grade. To describe the variation of lubricant viscosity with pressure, the Roelands' equation is used [33]:

$$
\eta(p)=\eta_{0} \exp \left\{\ln \left(\eta_{0}+9.67\right)\left[\left(1+5.1 \times 10^{-9} p\right)^{Z}-1\right]\right\}
$$

The PV index, Z, can be calculated according to Houpert [34] as:

$$
Z=\frac{\alpha^{*}}{5.1 \times 10^{-9} \ln \left(\eta_{0}+9.67\right)}
$$

where, $\alpha^{*}$ represents the reciprocal asymptotic iso-viscous pressure-viscosity coefficient, which is calculated at any given temperature according to Bair et al. [35] as:

$$
\alpha^{*}=\left[\int_{0}^{\infty} \frac{\eta\left(\mathrm{p}_{\mathrm{atm}}\right)}{\eta(\mathrm{p})} \mathrm{dp}\right]^{-1}
$$

The high pressure response of the viscosity under certain pressure is usually determined by the lubricant manufacturer through employing a falling body viscometer.

The high temperature response of the low shear dynamic viscosity at ambient (atmospheric) pressure is described by a Vogel-type equation [36] as:

$$
\eta_{0}(T)=\eta_{0, \text { ref }} \exp \left(\frac{A_{1}}{T-T_{0, \text { ref }}}\right)
$$

A cone-type rheometer was employed to measure the lubricant viscosity for a wide range of temperatures, namely between $10^{\circ} \mathrm{C}$ and $140^{\circ} \mathrm{C}$ with $1{ }^{\circ} \mathrm{C}$ increment. Table 2 lists the main properties of the various axle lubricants under examination.

Table 2: Properties of employed lubricants

\begin{tabular}{llll}
\hline Lubricant & $\boldsymbol{\eta}_{\mathbf{0}, \text { ref }}(\mathbf{P a} . \mathbf{s})$ & $\mathbf{A}_{\mathbf{1}}(\mathbf{K})$ & $\boldsymbol{\alpha}^{*}$ at $\mathbf{4 0} \mathbf{C}^{\circ}\left(\mathbf{P a}^{\mathbf{1}}\right)$ \\
\hline $\mathbf{1}$ & $1.55 \times 10^{-4}$ & 944.8 & $1.609 \times 10^{-8}$ \\
$\mathbf{2}$ & $7.47 \times 10^{-5}$ & 1105.0 & $1.931 \times 10^{-8}$ \\
$\mathbf{3}$ & $1.34 \times 10^{-4}$ & 943.0 & $1.627 \times 10^{-8}$ \\
\hline
\end{tabular}

\subsection{Thermal analysis}

The temperature rise at the central region of the teeth conjunction is estimated by employing an analytical methodology which is based on the approach followed by Olver [37]. Ultimately, the purpose of the thermal model is to estimate the average temperature rise at the central region of the EHD conjunction between the meshing teeth. Consequently, this permits a more accurate determination of the viscosity of the lubricant at the centre of the conjunction and eventually its frictional behaviour [25].

As already noted, the temperature of lubricant at the inlet meniscus is increased by $20{ }^{\circ} \mathrm{C}$ in comparison with its temperature in the sump. The lubricant temperature is expected to 
increase further at the central region of the conjunction because of friction, both due to the viscous shear of the lubricant and also due to potential asperity interactions. A lumped parameter thermal network model is used to evaluate the temperature rise in the contact (Figure 2).

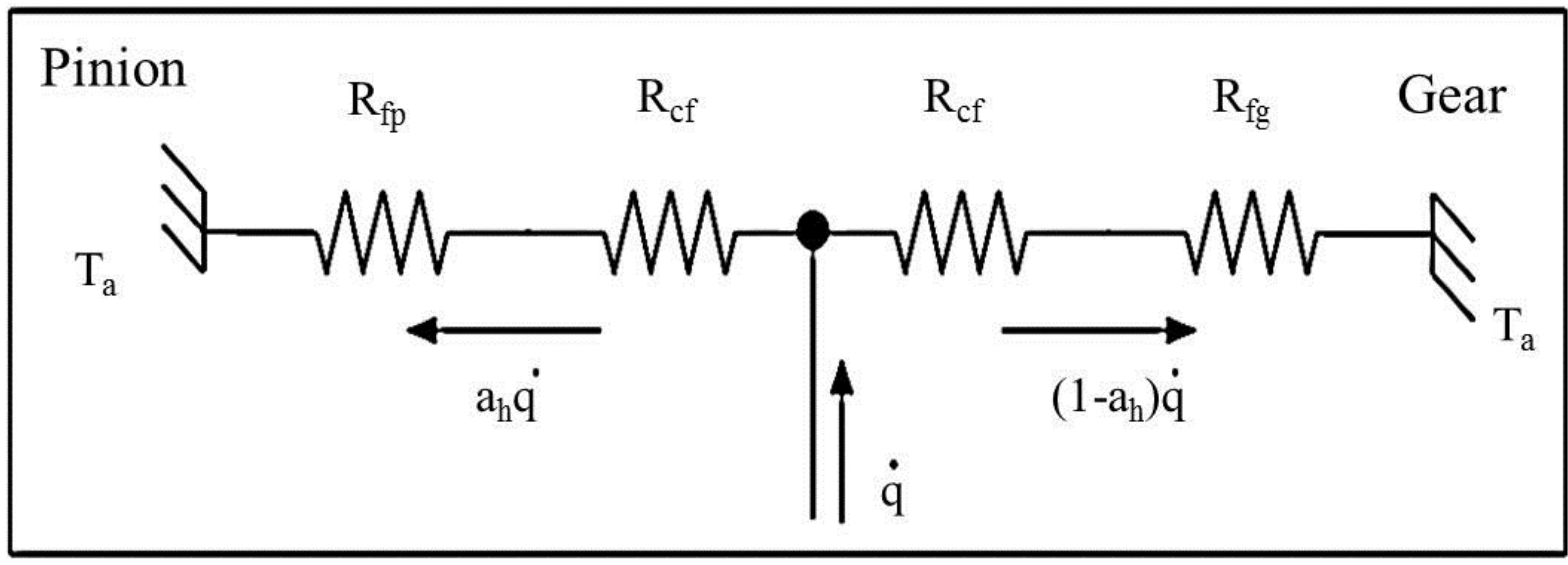

Figure 2: Thermal resistance model

A proportion of the heat produced due to friction at the centre of the conjunction $\dot{\mathrm{q}}=\left|\mathrm{F}_{\mathrm{fr}} \mathrm{V}_{\mathrm{s}}\right|$ is transferred to each bounding surface. This proportion is controlled by the heat partitioning coefficient, $a_{h}$. The side of the thermal network model correspond to the pinion (left hand side) and the ring gear (right hand side). It is assumed that the heat is produced at the midplane of contact between the pinion and gear teeth. The thermal resistance, $R_{c f}$, corresponds to the conduction of heat from the mid-plane to the adjacent solid surfaces. The thermal resistances, $R_{f p}$ and $R_{f g}$ represent the transient heat conduction to the solid surfaces according to Carslaw and Jaeger [38]. This approach has been employed in the study of circular point contact EHD by Olver [37]. In Figure 2, $\mathrm{T}_{\mathrm{a}}$ corresponds to the ambient temperature, which in this case is the temperature of the oil bath and $T_{b}$ is the temperature in the sump of the vehicular differential unit. The thermal resistances are:

$$
\mathrm{R}_{\mathrm{cf}}=\frac{\mathrm{h}_{\mathrm{c}}}{2 \mathrm{k}_{\mathrm{f}} \mathrm{A}_{\mathrm{EHL}}} \text {, and } \mathrm{R}_{\mathrm{fi}}=\frac{1.06}{\mathrm{~A}_{\mathrm{EHL}} \mathrm{k}_{\mathrm{s}}} \sqrt{\frac{\chi_{\mathrm{s}, \mathrm{i}} \mathrm{l}_{\mathrm{i}}}{\mathrm{U}_{\text {tot, }, \mathrm{i}}}}
$$

The methodology for calculating the thermal resistances is well-developed for the case of circular point contacts with no side leakage (lateral) velocity [25,37]. However, for the case of hypoid gear teeth conjunctions, the contact footprint is elliptical and the magnitude of the side leakage velocity is comparable to the velocity along the direction of entraining motion $[10,12,21]$. To take into account the effect of the complex contact geometry and kinematics on the transient heat conduction, Coleman's method [39] is adopted for the present analysis. This is accomplished by employing the active length parameter, $l_{\mathrm{i}}$. After utilising the original equations recommended by Coleman in [39], the active length for each side can be expressed as follows:

$$
\mathrm{l}_{\mathrm{i}}=\sqrt{\frac{\mathrm{a}_{\mathrm{c}}{ }^{2} \mathrm{~b}_{\mathrm{c}}{ }^{2}\left[\tan ^{2}\left(\theta_{\mathrm{i}}\right)+1\right]}{\mathrm{a}_{\mathrm{c}}{ }^{2}+\mathrm{b}_{\mathrm{c}}{ }^{2} \tan ^{2}\left(\theta_{\mathrm{i}}\right)}}
$$


where, $a_{c}$ and $b_{c}$ correspond to the lengths of the semi-major and the semi-minor axes of the elliptical contact footprint respectively. The angle $\theta_{\mathrm{i}}$ corresponds to the angle between the total surface velocity vector and the semi-minor axis of the contact ellipse. Hence, $\theta_{\mathrm{i}}$ can be calculated as: $\tan \left(\theta_{\mathrm{i}}\right)=\mathrm{v}_{\mathrm{s}, \mathrm{i}} / \mathrm{u}_{\mathrm{s}, \mathrm{i}}$.

According to [38], the heat partitioning coefficient and the average temperature at the centre of the conjunction are given by [37]:

$$
\begin{gathered}
\mathrm{a}_{\mathrm{h}}=\frac{\mathrm{R}_{\mathrm{fg}}+\mathrm{R}_{\mathrm{cf}}}{\mathrm{R}_{\mathrm{fp}}+\mathrm{R}_{\mathrm{fg}}+2 \mathrm{R}_{\mathrm{cf}}} \\
\overline{\mathrm{T}}_{\mathrm{c}}=\mathrm{T}_{\mathrm{in}}+\left(\Delta \mathrm{T}_{\mathrm{f}}\right)_{\mathrm{av}}+\left(\Delta \mathrm{T}_{\mathrm{oil}}\right)_{\mathrm{av}}
\end{gathered}
$$

where $\left(\Delta \mathrm{T}_{\mathrm{f}}\right)_{\mathrm{av}}$ represents the average flash temperature rise due to the presence of the moving heat source [38] whereas $\left(\Delta \mathrm{T}_{\mathrm{oil}}\right)_{\mathrm{av}}$ represents the average temperature rise of the lubricant due to shear heating and can be calculated as [37]:

$$
\left(\Delta \mathrm{T}_{\mathrm{f}}\right)_{\mathrm{av}}=\mathrm{R}_{\mathrm{fp}} \mathrm{a}_{\mathrm{h}} \dot{\mathrm{q}} \quad \text { and } \quad\left(\Delta \mathrm{T}_{\mathrm{oil}}\right)_{\mathrm{av}}=\frac{\left|\mathrm{v}_{\mathrm{s}}\right| \bar{\tau} \mathrm{h}_{\mathrm{cen}}}{8 \mathrm{k}_{\mathrm{f}}}
$$

It is expected that by adjusting the viscosity of the lubricant, based on the calculated contact temperature, the predicted friction and subsequent gear pair inefficiency can be predicted more accurately.

\subsection{Boundary friction}

The boundary friction can be calculated as [40]:

$$
\mathrm{F}_{\mathrm{b}}=\tau_{0} \mathrm{~A}_{\mathrm{asp}}+\mathrm{sW}_{\mathrm{asp}}
$$

This model accounts for two different sources of boundary friction. The product $\tau_{0} A_{\text {asp }}$ represents the shearing of a tribo-film present at the asperity summits. The shear strength of the tribo-film, $\tau_{0}$ is within the range determined experimentally by Briscoe and Evans [41]. The second source of boundary friction, which is taken into account in the product $s \mathrm{~W}_{\mathrm{asp}}$, originates from the cold welds formed between the asperities in the contact, where, $\mathrm{W}_{\text {asp }}$ is the load shared by the asperities and $\varsigma$ represents the coefficient of dry sliding friction of steel against steel in this case. Its value is taken to be $\varsigma=0.17$ according to De la Cruz et al. [42]. The load carried by the asperities is calculated by employing the Greenwood-Tripp model [15]. According to [15], the total load carried by the asperities and the total surface area within which inter-asperity contacts occur are:

$$
\begin{aligned}
& W_{\text {asp }}=\frac{8 \sqrt{2}}{15} \pi A_{E H L}\left(\eta_{G} \beta_{G} \sigma_{G}\right)^{2} \sqrt{\frac{\sigma_{G}}{\beta_{G}}} E^{\prime} F_{5 / 2}\left(\lambda_{s}\right) \\
& A_{\text {asp }}=\pi^{2} A_{E H L}\left(\eta_{G} \beta_{G} \sigma_{G}\right)^{2} F_{2}\left(\lambda_{s}\right)
\end{aligned}
$$

The parameters $\eta_{G}, \beta_{G}$ and $\sigma_{G}$, represent the surface density of the asperity peaks, the average radius of curvature of the asperity summits and the composite Root Mean Square (RMS) surface roughness of the mating surfaces. Greenwood and Tripp [15] suggest that for steel-on-steel contacts $0.03 \leq \eta_{\mathrm{G}} \beta_{\mathrm{G}} \sigma_{\mathrm{G}} \leq 0.05$. For the case of highly loaded hypoid gear pair teeth the lower limit of the recommended range may well be reduced during the run-in 
period. For that reason the $\eta_{\mathrm{G}}, \beta_{\mathrm{G}}$ and $\sigma_{\mathrm{G}}$ values are obtained individually for a specific runin hypoid pinion tooth surface, as described in Section 2.6. The value of the statistical functions $\mathrm{F}_{5 / 2}$ and $\mathrm{F}_{2}$ are calculated according to [40] as:

$$
\begin{aligned}
& F_{5 / 2}\left(\lambda_{s}\right)=-0.0046 \lambda_{s}^{5}+0.0574 \lambda_{s}^{4}-0.2958 \lambda_{s}^{3}+0.7844 \lambda_{s}^{2}-1.0776 \lambda_{s}+0.6167 \\
& F_{2}\left(\lambda_{s}\right)=-0.0018 \lambda_{s}^{5}+0.0281 \lambda_{s}^{4}-0.1728 \lambda_{s}^{3}+0.5258 \lambda_{s}^{2}-0.8043 \lambda_{s}+0.5003
\end{aligned}
$$

\subsection{Flank surface topography}

In order to calculate the boundary friction where interactions between asperity pairs on the counter face surfaces occur, the surface profile of a run-in pinion tooth was measured. Two different techniques for determining the surface topography were employed: one optical and another mechanical. The optical technique is based on the principle of focus variation, where an Alicona ${ }^{\mathrm{TM}}$ optical microscope was used (Figure 3, left hand side). A rotational unit (rotating head) was attached to the machine table to mount the pinion.

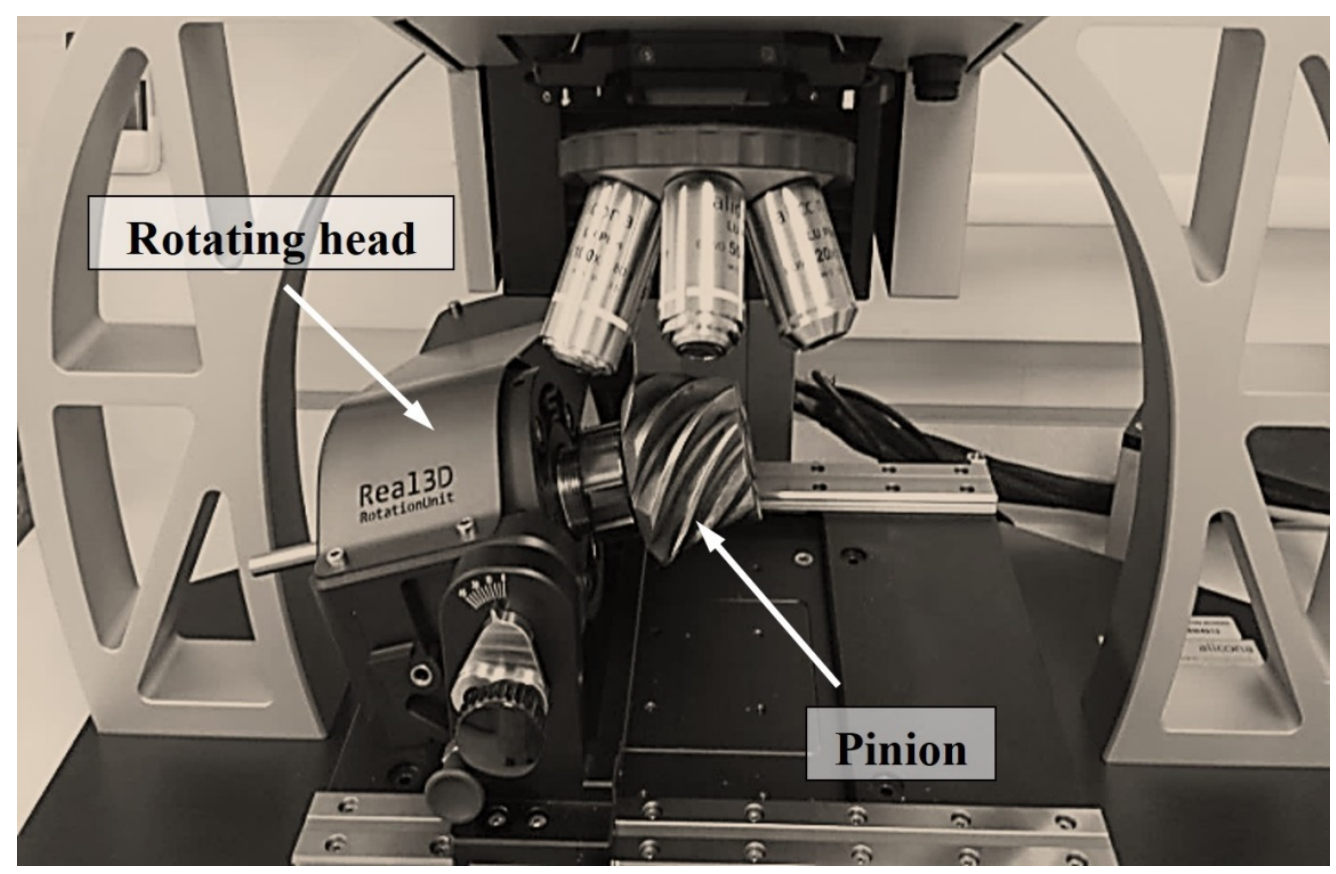




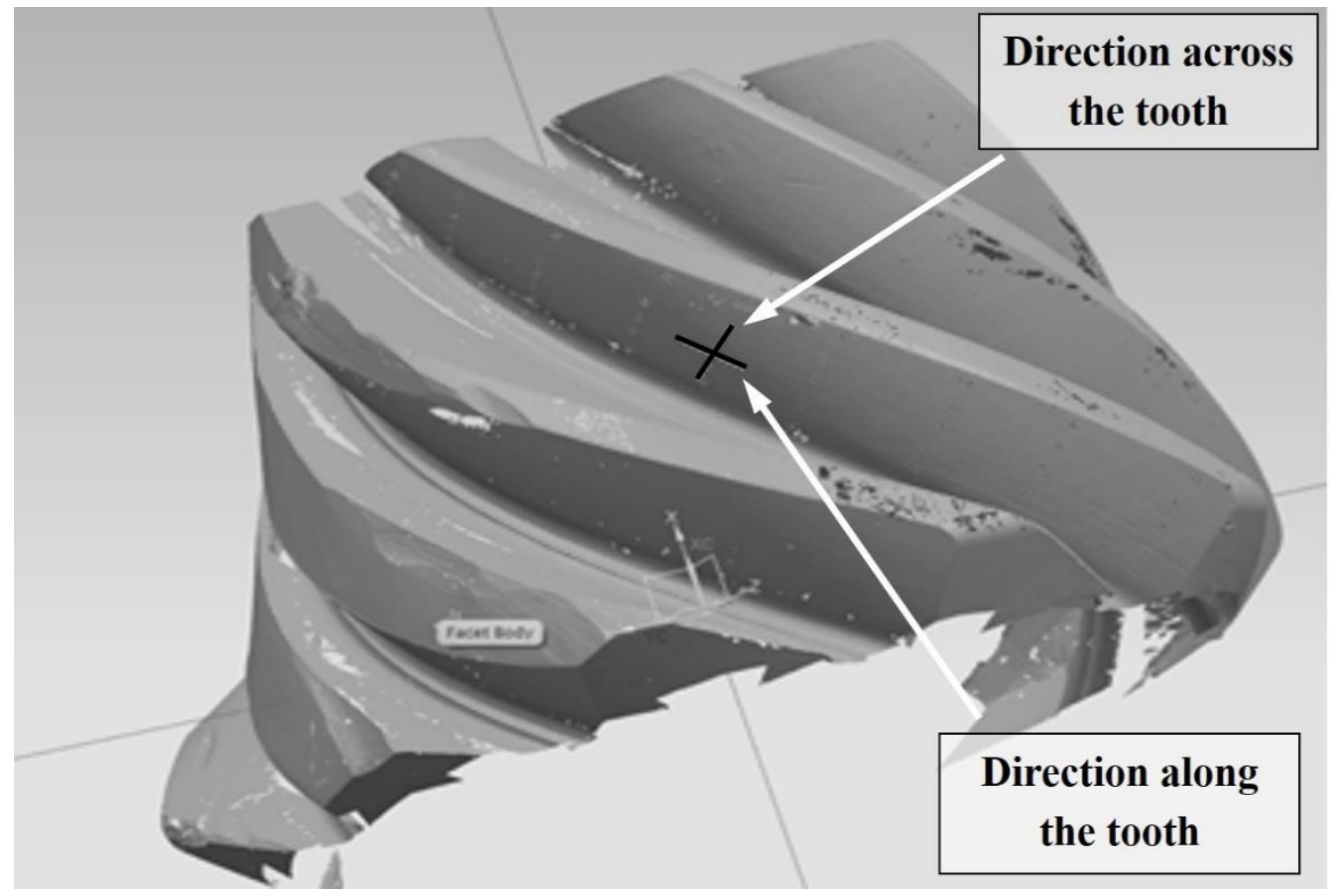

Figure 3: Mounting of the pinion on the optical microscope (up) and the resulting measured surface (bottom)

Once the sample (pinion) has been placed on the rotational unit, the microscope is focused on regions of interest on the tooth flank. The upper and lower focus boundaries are set. Crosssectional images are taken in between these boundaries. The compilation of those images yields a 2D surface topography of the pinion tooth at the points of interest (Figure 4a).

Six surface profiles along the axial and radial directions of tany tooth were obtained with a set of two profiles each on the heel, the middle and the toe of the tooth. It was observed that the surface roughness parameters for each of these three profiles (yellow lines in Figure 3, right) were of similar magnitude. With these surface profiles, the Greenwood-Tripp parameters were calculated based on the procedure highlighted by Arcoumanis et al. [16]. 

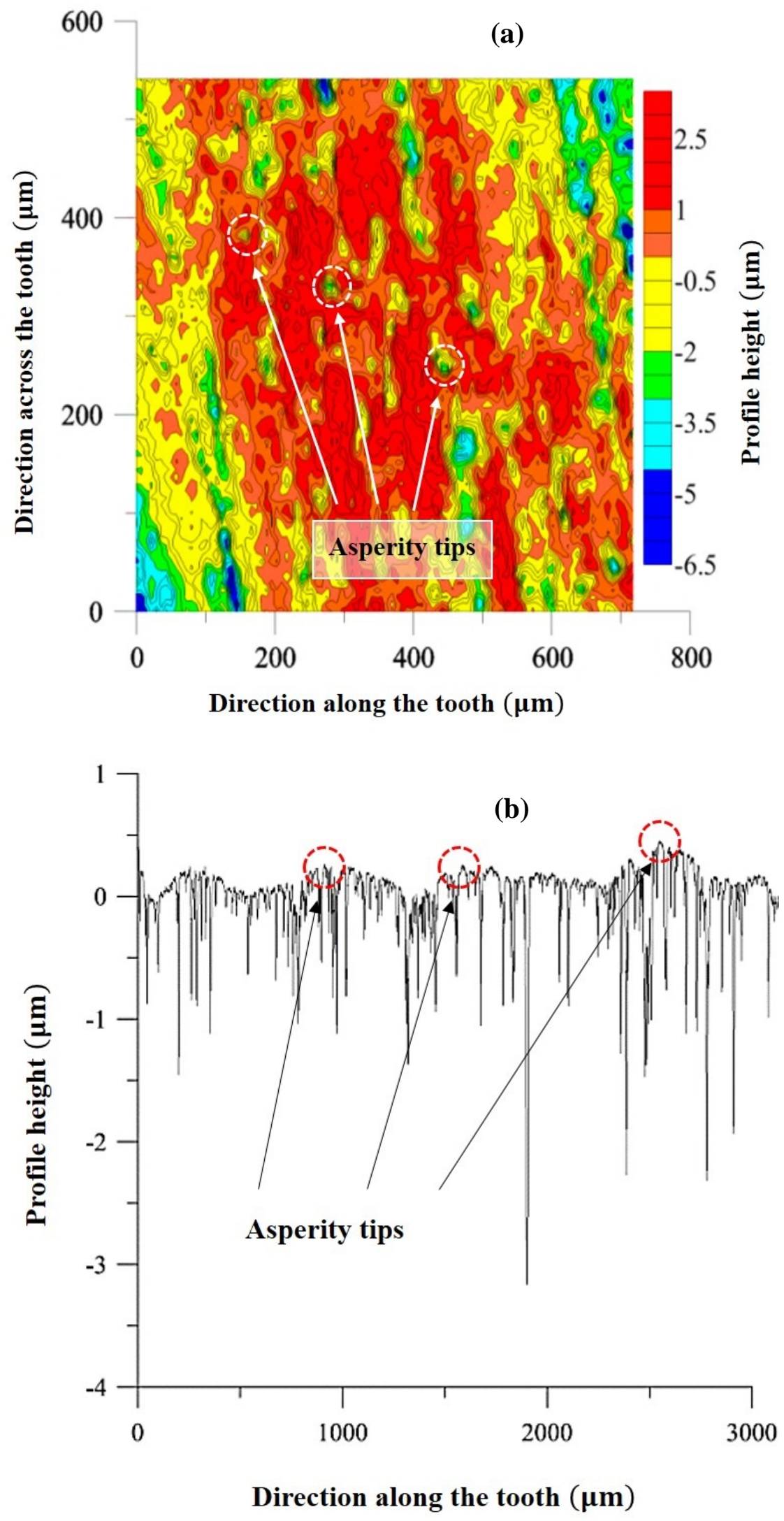

Figure 4: (a) 2D and the corresponding (b) 1D cross sectional surface topography of the pinion tooth surface 
Three spectral moments can be determined according to McCool [43]:

$$
\mathrm{m}_{0}=\overline{\mathrm{z}^{2}(\mathrm{x})}, \mathrm{m}_{2}=\overline{\left(\frac{\mathrm{dz}(\mathrm{x})}{\mathrm{dx}}\right)^{2}}, \mathrm{~m}_{4}=\overline{\left(\frac{\mathrm{d}^{2} \mathrm{z}(\mathrm{x})}{\mathrm{dx}^{2}}\right)^{2}}
$$

In order to account for the roughness profile along the axial and radial directions of the pinion teeth, the three spectral moments (equations 45) are calculated along these directions. The spectral moments are calculated twice for any pinion tooth surface (once along the axial direction and then along the radial direction) and twice for any gear flank surface. In the current study the corresponding gear tooth surface profile has not been determined since it is assumed that it is exactly the same as the pinion tooth surface profile. The choice of the axial and radial directions of the pinion tooth for the determination of the spectral moments was made because the minimum and maximum surface roughness is observed along these directions. This is due to the fact that the axial direction of the tooth almost coincides with the direction of the polishing wear tracks. According to Sayles and Thomas [44], the equivalent isotropic spectral moments of each of the surfaces (of the pinion and the gear) are obtained as:

$$
\mathrm{m}_{0 \mathrm{e}}^{\mathrm{i}}=0.5\left(\mathrm{~m}_{0 \mathrm{a}}^{\mathrm{i}}+\mathrm{m}_{0 \mathrm{r}}^{\mathrm{i}}\right), \mathrm{m}_{2 \mathrm{e}}^{\mathrm{i}}=\sqrt{\mathrm{m}_{2 \mathrm{a}}^{\mathrm{i}}+\mathrm{m}_{2 \mathrm{r}}^{\mathrm{i}}}, \mathrm{m}_{4 \mathrm{e}}^{\mathrm{i}}=\sqrt{\mathrm{m}_{4 \mathrm{a}}^{\mathrm{i}}+\mathrm{m}_{4 \mathrm{r}}^{\mathrm{i}}}
$$

where the superscript i refers to either of pinion or gear teeth surface. The subscripts a and $r$ refer to the axial and radial directions of any tooth surface. Finally, equivalent isotropic moment for the composite interface becomes:

$$
\mathrm{m}_{\mathrm{n}, \mathrm{ce}}=\mathrm{m}_{\mathrm{ke}}^{\mathrm{p}}+\mathrm{m}_{\mathrm{ke}}^{\mathrm{g}}
$$

where the subscript $\mathrm{n}$ represents the spectral moment to be determined and superscripts $\mathrm{p}$ and $g$ represent the pinion and gear teeth surfaces respectively. Based on the obtained equivalent combined isotropic spectral moments, the Greenwood-Tripp parameters can be calculated according to Longuet-Higgins [45] and Bush et al. [46] as:

$$
\eta_{\mathrm{G}}=\frac{1}{6 \pi \sqrt{3}} \frac{\mathrm{m}_{4, \mathrm{ce}}}{\mathrm{m}_{2, \mathrm{ce}}}, \beta_{\mathrm{G}}=0.375 \sqrt{\frac{\pi}{\mathrm{m}_{4, \mathrm{ce}}}}, \sigma_{\mathrm{G}}=\sqrt{\mathrm{m}_{0, \mathrm{ce}}}
$$

\section{Results and Discussion}

A flowchart of the solution procedure is provided in the Appendix. Initially, the friction model is validated against experimental friction measurements of Habchi et al. [47]. Then, the friction model is combined with the gear dynamics model. Predictions for several outputs of significant interest such as the conjunctional mechanical inefficiency, the dynamic transmission error, the contribution of the asperity friction on the average flank temperature rise at the centre of the gear teeth conjunctions are shown and discussed below.

\subsection{Validation of the friction model}

To examine the validity of predictions of the friction model, the results from the model are compared with experimental friction measurements data presented in [47], where a Mini Traction Machine (MTM) was employed. In this case, the lubricant used was a mineral oil. Figure 5 illustrates the variation of the coefficient of friction with the Slide-Roll Ratio (SRR) for two different loading conditions. The magnitude of the entraining velocity is kept constant at $\mathrm{U}=2 \mathrm{~m} / \mathrm{s}$ for both cases. 


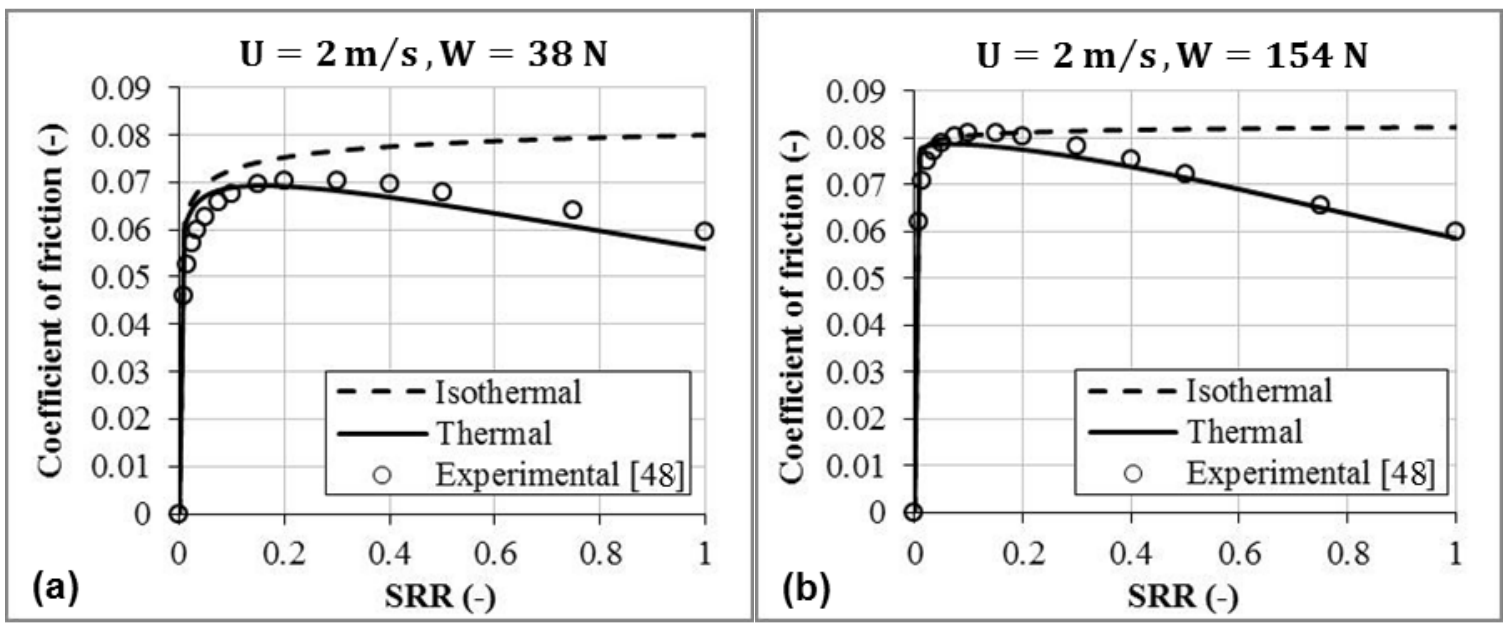

Figure 5: Comparison of the predictions of the friction model against the experimental data in [46] for (a) $W=38 \mathrm{~N}$ and (b) $W=154 \mathrm{~N}$

Figure 5 suggests that there is good agreement between the experimentally measured coefficient of friction and the corresponding predictions from the friction model in the current study, particularly when the thermal effects are considered. A key aspect of the results shown in Figure 5 is the importance of using a suitable thermal model to predict the observed reduction in traction with slide-to-roll ratios in the reported experimental works. It is also observed that the predictions of the friction model can be considered valid for a wide range of loading conditions from $38 \mathrm{~N}$ to $154 \mathrm{~N}$, which in turn correspond to maximum contact pressures of $0.85 \mathrm{GPa}$ to $1.35 \mathrm{GPa}$. The aforementioned range of contact pressures, along with the magnitude of the entraining velocity are typical in highly loaded hypoid gear pair conjunctions of automotive differentials [26]. The results from the current validation procedure should only be confined to the studied cases. For operating conditions other than those reported here, a separate validation procedure may be required, although a wide range of representative conditions are included in the current study.

\subsection{The tribo-dynamics model}

As noted earlier, three different axle fluids are examined, which are API Group IV lubricants with the base oil Poly-alpha-olefin (PAO). The additive pack both in terms of percentage and composition were common except for the blended VM type and the percentage. For Fluid 1, the VM is an ester-olefin copolymer, for Fluid 2 it is polyisobutylene, whereas for Fluid 3 it is polyethylene-co-propylene. All three fluids are examined in terms of their contribution to the conjunctional inefficiency and are compared with each other.

Figure 6 illustrates the maximum, minimum and mean DTE responses when Lubricant 1 is considered. The dashed line represents the half backlash length, meaning that when the minimum DTE response falls below this line, single-sided impacts occur between the meshing teeth. These vibro-impacts are the results of loss of contact between the meshing teeth for certain intervals of time during the meshing cycle. Single-sided impacts are clearly 
demonstrated in Figure 6. They are supressed by an increasing cruising velocity. This is due to the fact that for input torque $\mathrm{T}_{\mathrm{s}} \approx 25 \mathrm{Nm}$, the $1^{\text {st }}$ primary resonance appears, leading to high amplitude vibrations. When the contact between the mating teeth is lost, the flank friction diminishes, as seen in Figure 7.

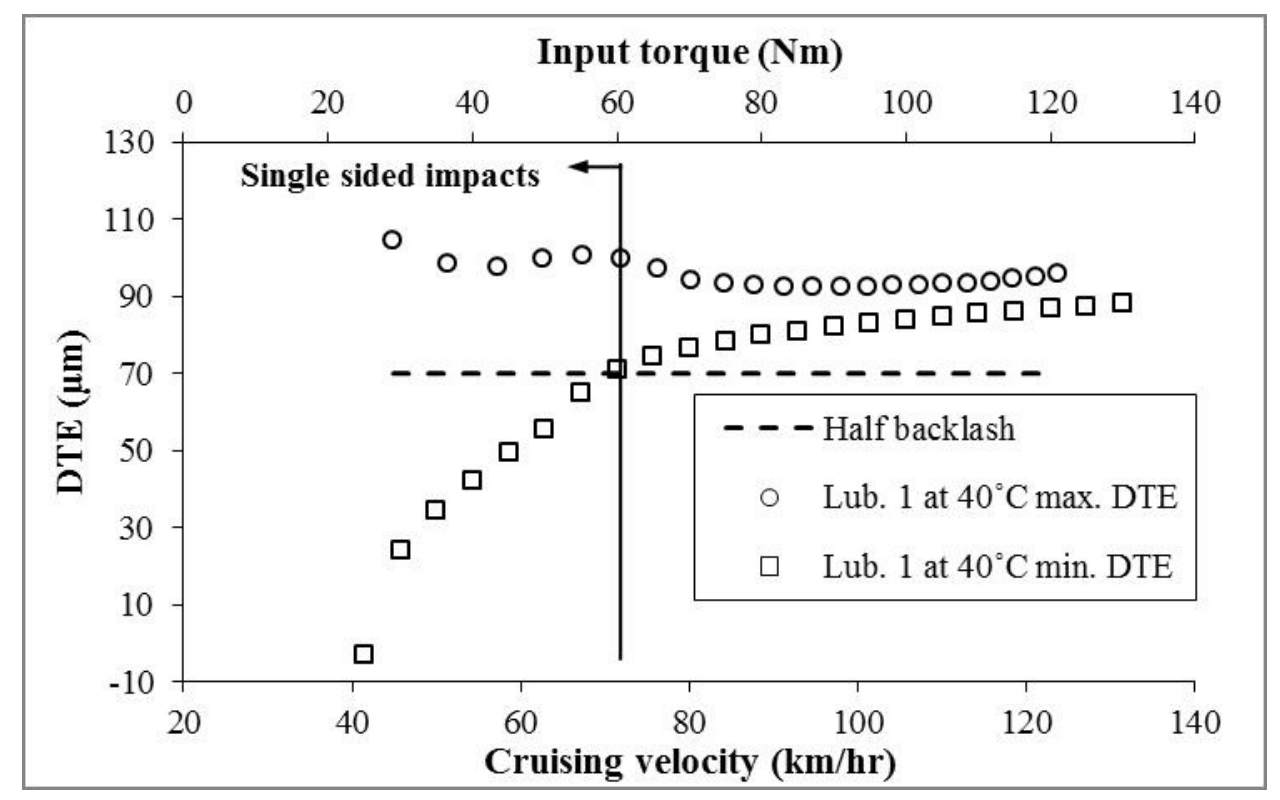

Figure 6: Minimum and maximum response of the DTE for Lubricant 1

Figure 7 presents the maximum, minimum and the mean frictional torque responses of the pinion for a range of cruising velocities. When single-sided impacts occur, for cruising velocities below $80 \mathrm{~km} / \mathrm{hr}$, the minimum frictional torque on the pinion diminishes, since within the meshing cycle the contact between the meshing teeth is lost for certain intervals. A rapid rise in the minimum friction torque occurs when there is no loss of contact. A subsequent decrease of the maximum response of the friction torque is also observed for increasing cruising velocities. This can be attributed to the improved film forming capabilities of the conjunction since the entraining velocity of the lubricant increases with the cruising velocity. Consequently, the contribution of the component of asperity friction also decreases with increasing cruising velocity, even though the contact load is increased. This is because the lubricant film thickness is quite sensitive to entraining velocity and insensitive to load under elastohydrodynamic regime of lubrication. This statement is further supported by the plots of figure 8. Regarding the mean frictional torque response, this remains virtually constant with the cruising velocity with only a slight increase at higher velocities. 


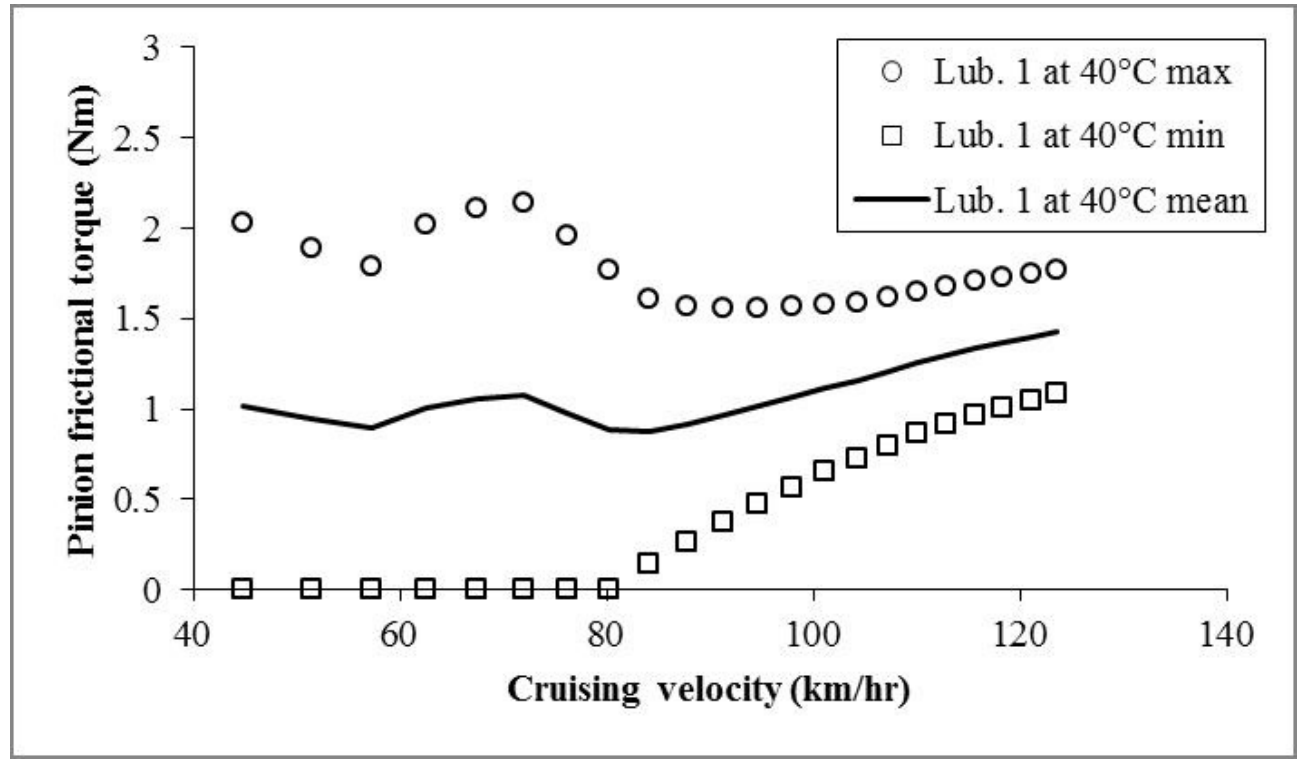

Figure 7: Minimum and maximum of the pinion friction torque for lubricant 1

Figure 8 presents the ratio of boundary-to-viscous friction for all the three lubricants examined. The temperature of the sump is set to $40^{\circ} \mathrm{C}$. The magnitudes of boundary and viscous friction used to calculate this ratio correspond to their RMS values for 50 meshing cycles under steady state conditions. The considerable influence of the component of boundary friction for low-medium cruising velocities is clearly demonstrated. A comparison amongst the three investigated fluids reveals that, in terms of film thickness formation capabilities, lubricants 1 and 3 behave in quite a similar manner. On the contrary, lubricant 2 behaves differently since the corresponding boundary-to-viscous friction ratio is significantly lower than that for Lubricants 1 and 3.

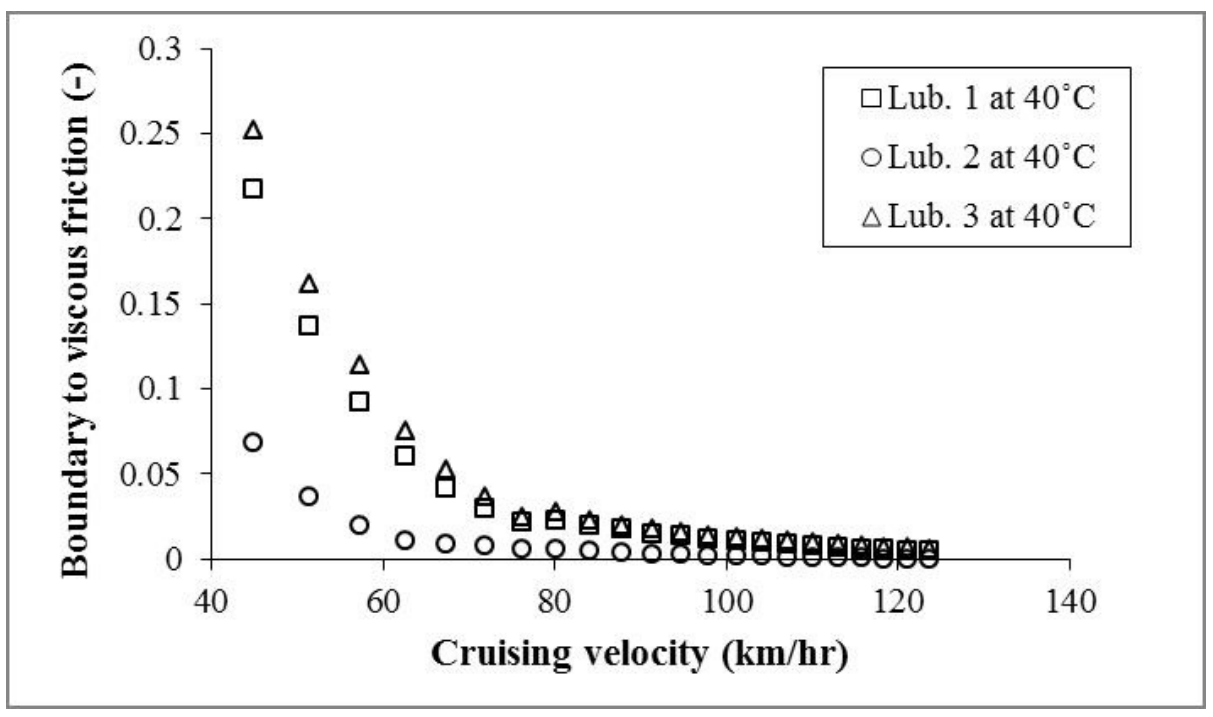

Figure 8: RMS of the boundary to viscous friction ratio for the three lubricants under examination 
Practically, this translates to Lubricant 2 exhibiting improved film forming capabilities over lubricants 1 and 3. To further support this statement, the variation of the central film thickness at $40{ }^{\circ} \mathrm{C}$ with the lubricant entraining velocity is presented in Figure 9 . The central film thickness is obtained experimentally by employing an optical interferometer which comprises a steel sphere, loaded against an optically flat glass disk. The maximum contact pressure is $0.5 \mathrm{GPa}$, with pure rolling conditions maintained throughout the range of examined entraining velocities. As shown in Figure 9, lubricant 2 demonstrates improved film forming capabilities over lubricants 1 and 3 even when a much simpler configuration, such as a sphere against a flat configuration is employed. Not only does this validate (qualitatively) the findings of the tribodynamic analysis (presented in Figure 8) but also it implies that rather simple and relatively cheap laboratory experiments, such as optical interferometry, can be safely used to estimate the film forming behaviour of the lubricants when employed in a full scale system such as a hypoid gear pair in a vehicular differential unit.

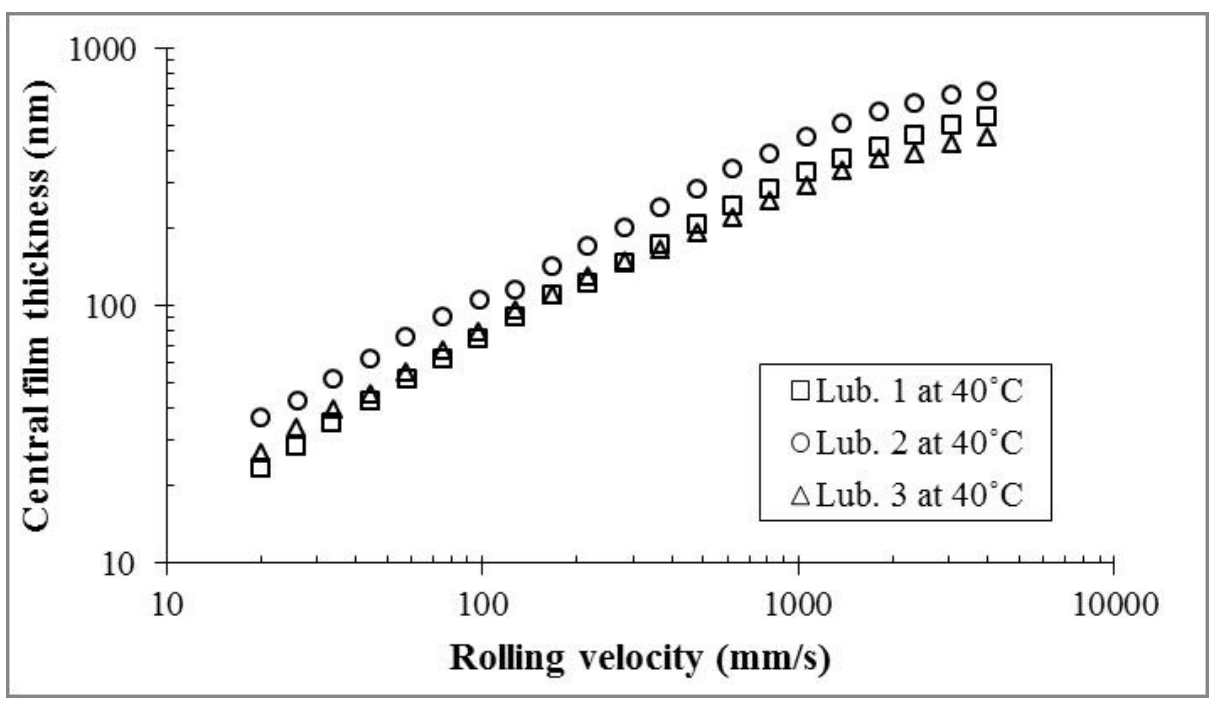

Figure 9: Experimental central film thickness using the optical interferometry rig

Figure 10 presents the variation of the conjunctional inefficiency of the gear pair with an increasing cruising velocity. The conjunctional inefficiency is defined as the ratio of the power loss to the input power, expressed as a percentage value. Lubricant 1 is employed while the temperature of the sump is maintained at $40{ }^{\circ} \mathrm{C}$ throughout. Both isothermal and thermal approaches are considered. The divergence between those two approaches is clearly demonstrated throughout the range of cruising velocities, highlighting the impact of thermal effects occurring at the centre of the EHD conjunction on the total system inefficiency. Again, the magnitude of the inefficiency for each velocity, corresponds to the RMS of the instantaneous inefficiency over 50 meshing cycles, under steady state conditions. The trend of the plots of Figure 10 also reveals that the conjunctional inefficiency reduces with increasing cruising velocity when the thermal effects are accounted for. This is in line with the findings of others [8,9] and can be attributed to the synergistic effect of the reduction of boundary friction and the increasing central flank temperature, which leads to a reduction of lubricant, hence reducing viscous friction. The inefficiency predictions under the isothermal assumption indicate an increase in the conjunctional inefficiency with the cruising velocity. 
This represents cold start-up conditions. This behaviour suggests that the thermal effects in the conjunction considerably improve its efficiency performance. The significance of the thermal effects on the conjunctional inefficiency, as well as the increase of the central flank temperature, are demonstrated by the plots of Figure 11, where the variation of the average temperature rise with the cruising velocity is presented for Lubricant 1 . Three different sump temperatures are examined.

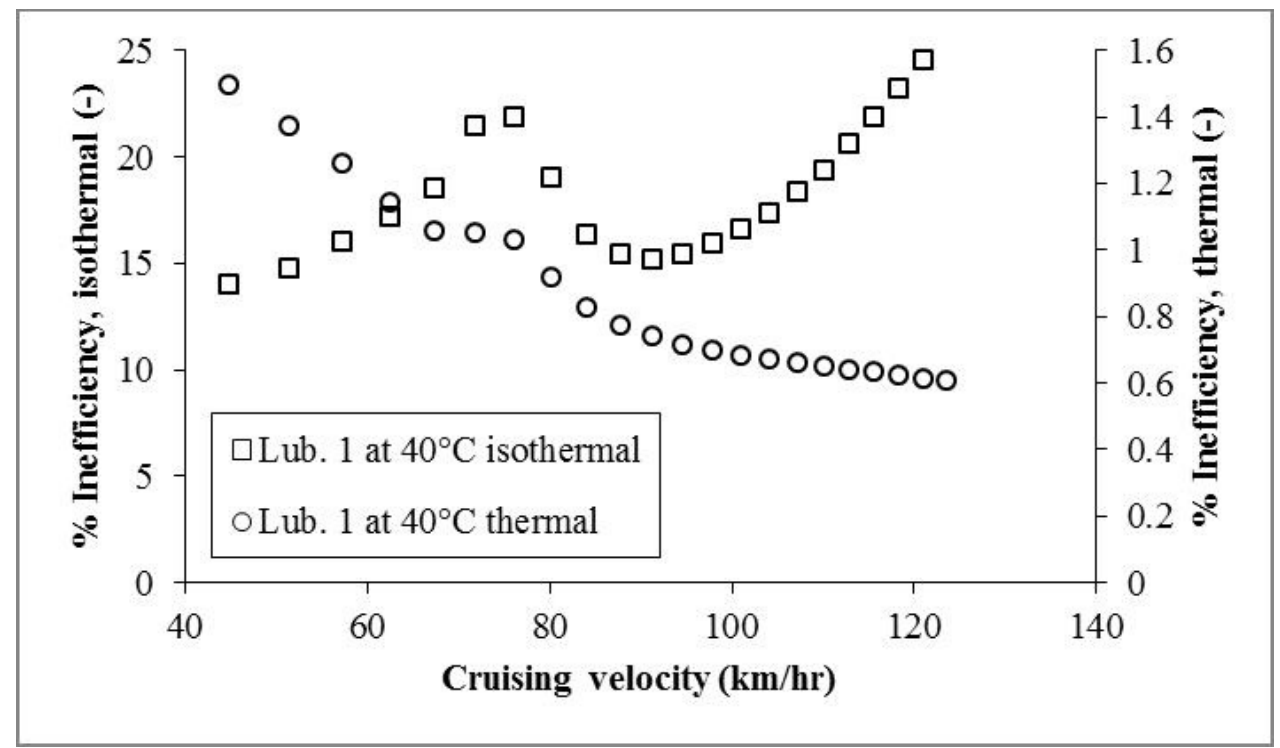

Figure 10: Comparison of the RMS inefficiency predictions for lubricant 1 between the isothermal and the thermal approaches

Figure 11 suggests that the average flank temperature rise at the centre of the EHD conjunction is considerably increases with cruising velocity. This is an expected outcome since increased cruising velocity also leads to increased tooth surface velocity, which results in increased shear heating of the lubricant. Additionally, it is suggested that the magnitude of the average flank temperature rise is reduced with an increasing sump temperature. This is also an expected outcome since increased sump temperature leads to increased inlet temperature as well. Consequently, the average temperature at the centre of the conjunction is also rises, leading to a relative decrease in the viscosity in the central region of the contact. Hence, the effect of shear heating is mitigated, leading to a reduced average temperature rise. 


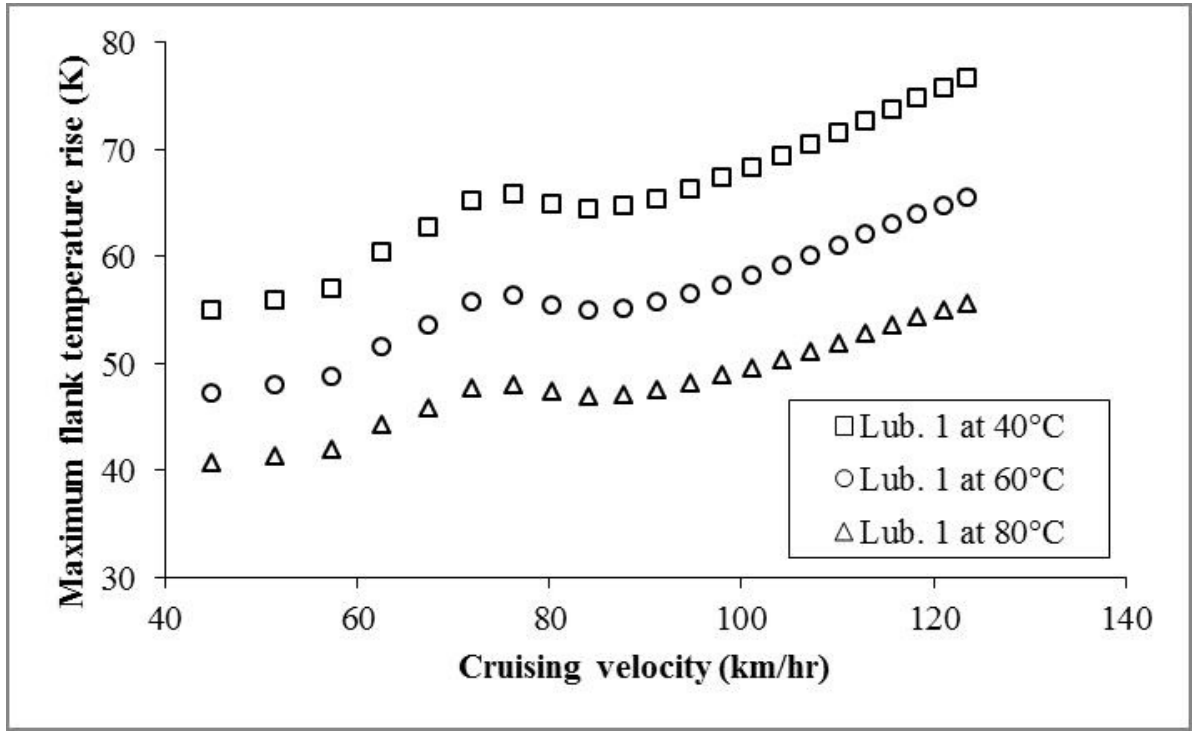

Figure 11: Maximum flank temperature at the centre of the conjunction for lubricant 1

Since increased oil sump temperature leads to a decrease in viscosity, it is also expected that the inefficiency would be reduced. This is supported by the plots presented in Figure 12, where Lubricant 1 is examined at three different oil sump temperatures.

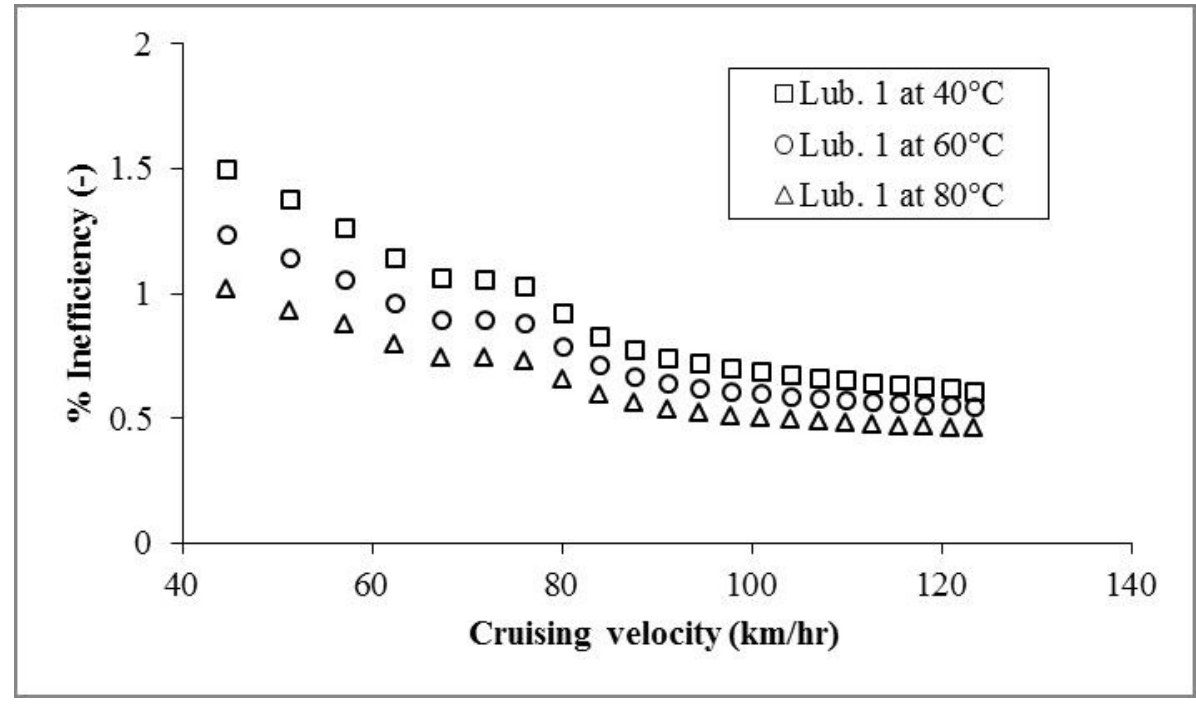

Figure 12: RMS inefficiency for lubricant 1 at different sump temperatures

The decrease in inefficiency with increasing oil sump temperature is clearly demonstrated in Figure 12, supporting the above statements. This is also in line with the observations of $\mathrm{Xu}$ and Kahraman [8], which were derived theoretically, as well as with the experimental work of Kubo et al. [3]. 


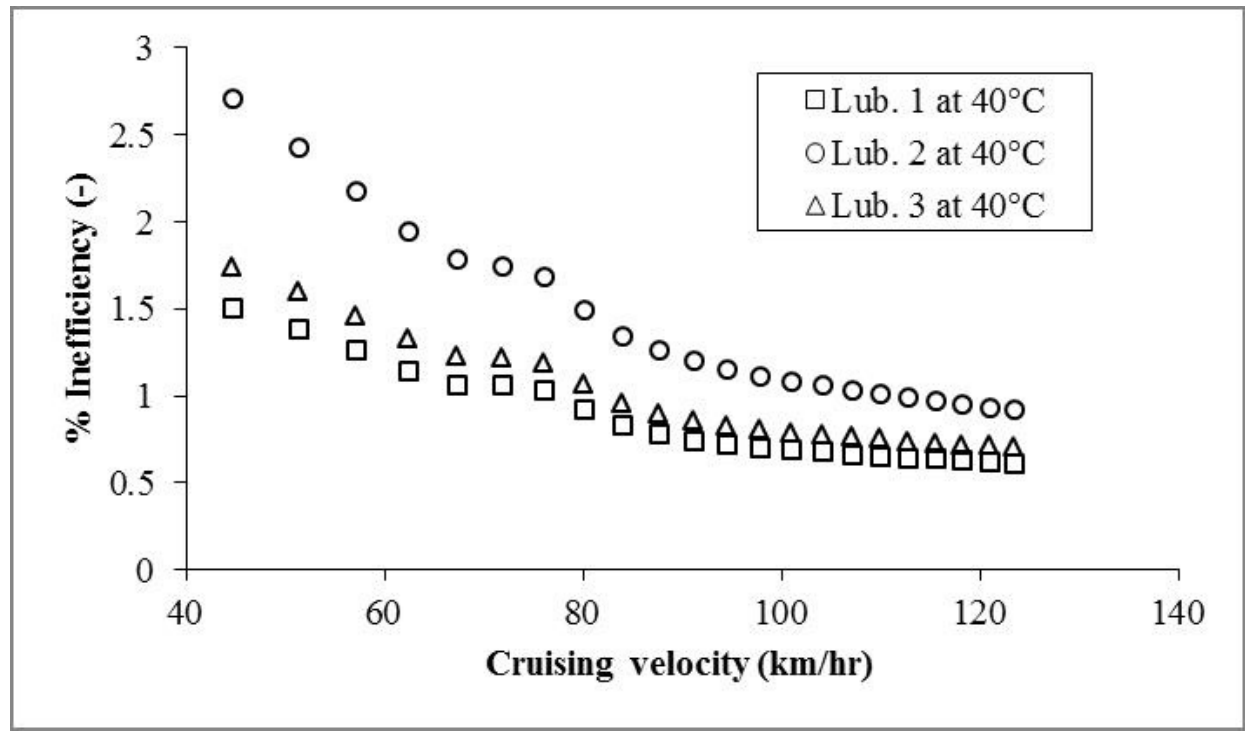

Figure 13: RMS inefficiency for the three lubricants under examination $\left(40^{\circ} \mathrm{C}\right.$ indicates bulk lubricant temperature at the start of simulation)

A comparison of the predicted conjunctional inefficiency amongst the three lubricants under examination is demonstrated in Figure 13. The plots indicate that Lubricants 1 and 3 not only exhibit very similar film formation behaviour, but also quite identical tractive behaviour, since their application results in similar inefficiency. Again Lubricant 2 seems to behave in a different manner. To further support the predictions of the tribodynamic model, the coefficient of friction for varying slide-roll ratios and at constant entraining velocity is experimentally determined for the three lubricants by employing a MTM. The configuration of the MTM is very similar to that of the optical interferometer, with a steel sphere loaded against a flat disk, also made of steel. The experimentally determined coefficient of friction is plotted against the slide-roll ratio in Figure 14. The maximum contact pressure is kept at $1 \mathrm{GPa}$, the entraining velocity is at $2.5 \mathrm{~m} / \mathrm{s}$, whilst the temperature of the oil bath is kept at $40{ }^{\circ} \mathrm{C}$ throughout.

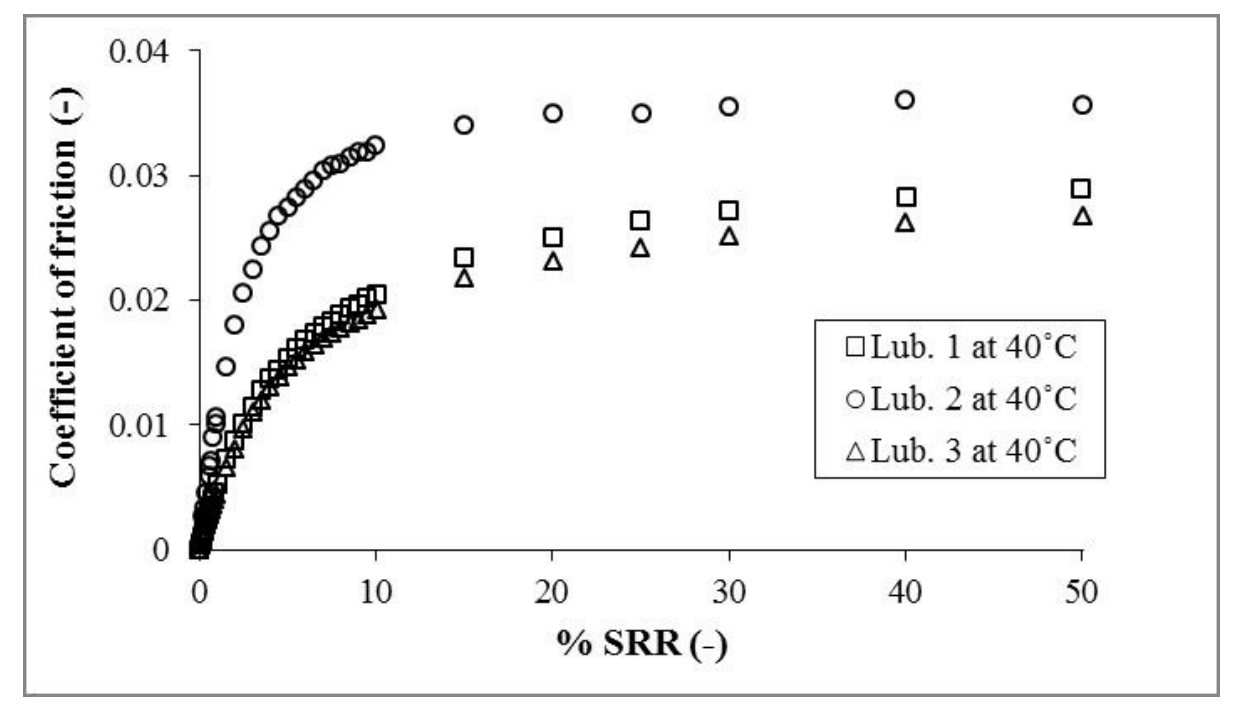

Figure 14: Experimental coefficient of friction using the $M T M$ for $U=2.5 \mathrm{~m} / \mathrm{s}\left(40^{\circ} \mathrm{C}\right.$ indicates bulk lubricant temperature at the start of simulation) 
The experimentally determined coefficient of friction, for the lubricants under examination, presented in Figure 14 validates, at least qualitatively, the predictions of the tribodynamic model. The considerably increased coefficient for Lubricant 2 over the rest is well demonstrated throughout the range of slide-roll ratios. A remark should be made regarding the comparison between Lubricants 1 and 3. The MTM data indicate that Lubricant 3 exhibits a slightly reduced coefficient of friction compared with Lubricant 1 . On the contrary, the corresponding inefficiency seems to follow the opposite trend. This can be attributed to the assumed independence of the limiting shear stress on the temperature. The difference between the coefficient of friction for Lubricant 2 and those of Lubricants 1 and 3 highlights the major influence of the viscosity modifier on friction and ultimately on the conjunctional inefficiency. A question that might arise concerns the mechanism through which the VM influences the inefficiency of the gear pair. Two possible mechanisms are considered in the present investigation, namely (1) through varying the high temperature response of the viscosity, and (2) through varying the high shear response of the viscosity. Although more investigation, both theoretical and experimental would be required in order to conclude, an attempt is made in the current study to shed some light on these issues. Figure 15 presents the inefficiency variation with cruising velocity for Lubricant 1 . Two cases are examined, namely (1) where the shear thinning action of this fluid is taken into account, and (2) where the shear thinning is neglected. The oil sump temperature is kept at $40{ }^{\circ} \mathrm{C}$. The plots indicate a very close convergence of the aforementioned approaches. This observation suggests that, at least when highly loaded hypoid gear pairs are considered at medium-high speeds, the shear thinning of the lubricants employed is kept relatively low. This is due to the fact that, as indicated in Figure 11, the average temperature at the centre of the conjunction is relatively high, and increases with the speed, leading to mitigation of the shear thinning action. It is well known that the shear thinning is mitigated with increasing temperatures [32].

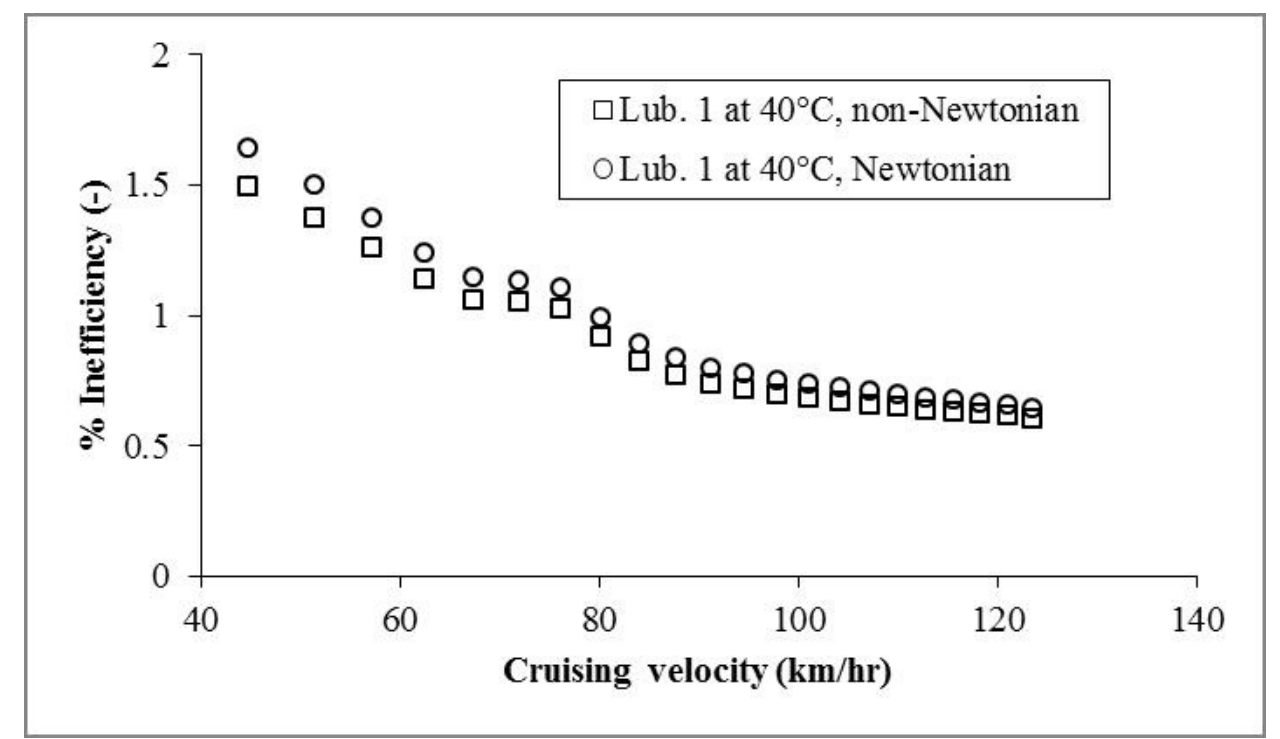

Figure 15: Comparison of the predicted inefficiency between the non-Newtonian and the Newtonian approaches $\left(40^{\circ} \mathrm{C}\right.$ indicates bulk lubricant temperature at the start of simulation) 
Finally, in Figure 16 the percentage difference between the inefficiency under Newtonian and non-Newtonian assumptions, is presented in order to further illuminate the plots of Figure 15. The results of Figure 16 suggest that not only the maximum difference between the two approaches is kept at $\sim 9.5 \%$, but also this difference reduces with an increasing speed. It is believed that this reduction is because of the prevailing thermal effects, at higher speeds, which tend to suppress the shear thinning action of the lubricants.

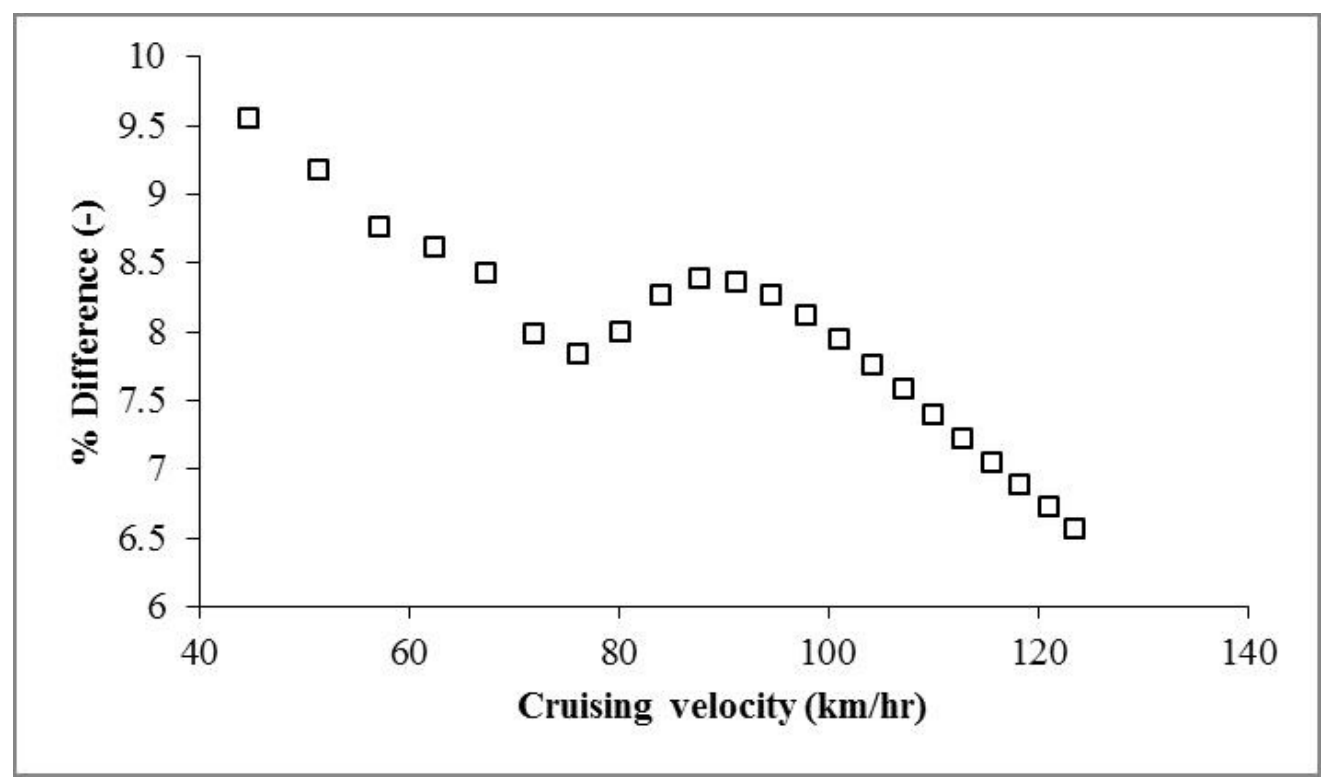

Figure 16: Percent difference between the inefficiency predictions using the Newtonian and the non-Newtonian approach

The results also indicate that the VM may affect the conjunctional inefficiency of hypoid gear pairs mainly through modifying their high temperature response rather than their high shear response. More investigation would be required to support this statement.

\section{Conclusions}

A tribo-dynamics analysis of a hypoid gear pair, corresponding to a differential unit of an automotive drivetrain is presented. A 4-DoF torsional gear dynamics model containing the exact data related to the gear tooth geometry is integrated with a friction model to predict the conjunctional inefficiency. The performance of three axle fluids, blended with different types of viscosity modifiers is examined.

The developed tribodynamic model found to be of sufficient "resolution" to distinguish the emerging differences between the performance of different nano-scale viscosity modifying additives with respect to their type and concentration, when their effect is measured with various test-rigs.

The findings of the present study can be summarised as follows:

- At lower speeds, the system inefficiency is increased due to the effect of boundary friction combined with reduced contact temperatures. 
- An increasing temperature of the oil sump leads to improved efficiency due to its effect in reducing viscous friction at the centre of the contact conjunction.

- The thermal effects occurring at the centre of the conjunction have a significant effect on the predicted conjunctional inefficiency (an order of magnitude difference is observed between the predictions of the isothermal and the thermal approaches).

- The information obtained through laboratory testing, using optical interferometry and MTM on the rheological behaviour of candidate lubricants can be directly related to their performance in real applications such as those encountered in automotive differentials.

- The shear thinning action of the studied lubricants is largely supressed when used in a hypoid gear pair of a vehicular differential. Hence, the quantitative differences in the system inefficiency between the fluids with different viscosity modifiers can be attributed to the contribution of the VM.

The main contribution of the current study is the link established between lubricant rheological properties, particularly the type of viscosity modifiers and percentage concentration, and gear pair dynamics, as well as transmission efficiency.

The current study can be improved further by developing a more elaborate boundary friction model, which is able to take into account the effect of (chemically and/or physically) adsorbed layers on the surfaces altering the conjunctional frictional behaviour in addition to the bulk lubricant film effects.

\section{References}

[1] Mohammad-Pour, M., "Transient Tribo-Dynamics of Differential Hypoid Gear Pair",. PhD Thesis, Loughborough University, uk 2014.

[2] Goodwin, M.C. and Haviland, M.L, "Fuel Economy Improvements in EPA and Road Tests with Engine Oil and Rear Axle Lubricant Viscosity Reduction", SAE Tech Pap 1979;780596:2206-24.

[3] Kubo, K., Shimakawa, Y. and Kibukawa, M., "The Effect of Gear Oil Viscosity and Friction Reducer Type on Transmission Efficiency", Tribol Int., 1986, 19:312-317.

[4] Gangopadhyay, A., Asaro, S., Schroder, M., Jensen, R. and Sorab, J., "Fuel Economy Improvement Through Frictional Loss Reduction in Light Duty Truck Rear Axle", SAE Tech Pap 2002, Pap. No. 2002-01-28.

[5] Kolekar, A.S., Olver, A.V., Sworski, A.E. and Lockwood, F.E., "The Efficiency of a Hypoid Axle-a Thermally Coupled Lubrication Model", Tribol Int 2013, 59:203209.

[6] Simon, V., "Elastohydrodynamic Lubrication of Hypoid Gears", J Mech Des 1981, 103:195-203.

[7] Xu, H., Kahraman, A. and Houser, D.R., "A Model to Predict Friction Losses of Hypoid Gears", AGMA Tech. Pap, 2005:1-15. 
[8] Xu, H. and Kahraman, A., "Prediction of Friction-Related Power Losses of Hypoid Gear Pairs", Proc IMechE, Part K: J Multi-Body Dyn., 2007, 221:387-400.

[9] Kolivand, M., Li, S. and Kahraman, A., "Prediction of Mechanical Gear Mesh Efficiency of Hypoid Gear Pairs", Mech Mach Theory, 2010, 45:1568-1582.

[10] Mohammadpour, M., Theodossiades, S. and Rahnejat, H., "Elastohydrodynamic lubrication of hypoid gear pairs at high loads", Proc IMechE, Part J: J Eng Tribol., 2012, 226:183-198.

[11] Mohammadpour, M., Theodossiades, S., Rahnejat, H. and Saunders, T., "NonNewtonian mixed elastohydrodynamics of differential hypoid gears at high loads", Meccanica 2013, 49:1115-1138

[12] Karagiannis, I., Theodossiades, S. and Rahnejat, H., "On the dynamics of lubricated hypoid gears", Mech Mach Theory 2012, 48:94-120.

[13] Mohammadpour, M., Theodossiades, S., Rahnejat, H. and Kelly, P., "Transmission efficiency and noise, vibration and harshness refinement of differential hypoid gear pairs", Proc IMechE, Part K J Multi-Body Dyn., 2014, 228(1):19-33

[14] Mohammadpour, M., Theodossiades, S. and Rahnejat, H., "Tribo-Dynamics of Differential Hypoid Gears", Proc ASME Int Des Eng Tech Conf Comput Inf Eng Conf 2013:1-9.

[15] Greenwood, J.A. and Tripp, J.H., "The contact of Two Nominally Flat Rough Surfaces", Proc IMechE, 1970-1971,185:625-633.

[16] Arcoumanis, C., Ostovar, P. and Mortier, R., "Mixed Lubrication Modelling of Newtonian and Shear Thinning Liquids in a Piston-Ring Configuration", Int. Fall Fuels Lubr Meet Expo Tulsa, Oklahoma, Oct 13-16 1997:35-60.

[17] Kahraman, A. and Singh, R., "Non-Linear Dynamics of a Spur Gear Pair", J. Sound and Vib., 1990, 142:49-75.

[18] Bosch, R., "Automotive Handbook", Robert Bosch GmbH 2004; Postfach:Germany.

[19] Karagiannis, I., "Tribo-dynamic Analysis of Hypoid Gear Pairs in Automotive Differentials", PhD Thesis, Loughoborough Univ , 2013.

[20] Mohammadpour, M., Theodossiades, S. and Rahnejat H., "Multiphysics Investigations on the Dynamics of Differential Hypoid Gears", J Vib Acoust.,2014, 136:041007.

[21] Paouris, L., Theodossiades, S., De la Cruz, M., Rahnejat, H., Kidson, A., Hunt, G. and Barton, W., "Film Thickness Investigation in Heavily Loaded Hypoid Gear Pair Elastohydrodynamic Conjunctions", STLE, 70th Annu. Meet Exhib., Dallas, Texas, USA 2015.

[22] Venner, C. H and ten Napel, W. E., "Surface Roughness Effects in EHL Line Contact", Trans ASME J. Tribol., 1992, 114: 612-622 
[23] Chittenden, R.J., Dowson, D., Dunn, J.F. and Taylor, C.M., "A Theoretical Analysis of the Isothermal Elastohydrodynamic Lubrication of Concentrated Contacts. I. Direction of Lubricant Entrainment Coincident with the Major Axis of the Hertzian Contact Ellipse", Proc Roy. Soc., A-Math Phys Eng Sci, 1985;397:245-69.

[24] Olver, A. V., "Gear Lubrication - a review", Proc. IMechE, Part J: J Eng Tribol., 2002, 216:255-267.

[25] Paouris, L., Rahmani, R., Theodossiades, S., Rahnejat, H., Hunt, G., and Barton, W., "An analytical approach for prediction of elastohydrodynamic friction with inlet shear heating and starvation", Tribology Letters, 2016, 64(1), 10

[26] Olver, A. V. and Spikes, H. A., "Prediction of Traction in Elastohydrodynamic Lubrication", Proc IMechE, Part J: J. Eng Tribol.,1998, 212:321-332.

[27] Paouris, L., Theodossiades, S., De la Cruz, M., Rahnejat, H., Kidson, A., Hunt, G. and Barton, W., "Tribodynamics Analysis and Sub-surface Stress Field of an Automotive Differential Hypoid Gear Pair", Proc. IMechE, Part C: J. Mech. Eng. Sci., 2016, 230(7-8):1183-1197.

[28] Stachoviak, G.W.and Batchelor, A.W., "Engineering Tribology", Butterworth Heineman, 2001:744.

[29] Hamrock, B.J. and Dowson, D., "Ball Bearing Lurication-The Elastohydrodynamics of Elliptical Contacts", John Willey \& Sons, 1981.

[30] Hoglund, E. and Jacobson, B., "Experimental Investigation of the Shear Strength of Lubricants Subjected to High Pressure and Temperature", J. Tribol., 1986, 108:571577.

[31] Havriliak, S. and Negami, S., "A complex plane representation of dielectric and mechanical relaxation processes in some polymers", Polymer (Guildf), 1967, 8:161210 .

[32] Williams, M.L., Landel, R.F. and Ferry, J.D., "The Temperature Dependence of Relaxation Mechanisms in Amorphous Polymers and Other Glass-forming Liquids", J. Am. Chem. Soc., 1955,77:3701-3707.

[33] Bair, S., "High Pressure Rheology for Quantitative Elastohydrodynamics", Tribol. Interface Eng. Ser. 2007, Elsevier.

[34] Roelands, C., "Correlational Aspects of the Viscosity-Temperature Pressure Relationship of Lubricating Oils", Delft Univ. Tech., 1966.

[35] Houpert, L., "New results of traction force calculations in elastohydrodynamic contacts", J. Tribol., 1985, 107:241-248.

[36] Bair, S., Liu, Y. and Wang, Q.J., "The Pressure-Viscosity Coefficient for Newtonian EHL Film Thickness With General Piezoviscous Response", J. Tribol., 2006, 128:624. 
[37] Cameron, A., "Principles of Lubrication", Longmans Green Co Ltd ,1966.

[38] Olver, A V., "Testing Transmission Lubricants: the Importance of Thermal Response", Proc IMechE, Part G: J. Aerosp. Eng., 1991, 205:35-44.

[39] Carslaw, H.S. and Jaeger, J.C., "Conduction of heat in solids", Oxford Clarendon Press, 1959, 2nd ed.

[40] Coleman, W., "A Scoring Formula for Bevel and Hypoid Gear Teeth", J. Tribol., 1967, 89:114-123.

[41] Gohar, R. and Rahnejat, H., "Fundamentals of Tribology", Imperial College Press, London, 2008.

[42] Briscoe, B.J. and Evans, D.C.B., "The Shear Properties of Langmuir-Blodgett Layers", Proc. Roy. Soc., London, 1982, 380:389-407.

[43] De la Cruz, M., Chong, W.W.F., Teodorescu, M., Theodossiades, S. and Rahnejat, H., "Transient mixed thermo-elastohydrodynamic lubrication in multi-speed transmissions", Tribol. Int., 2012, 49:17-29.

[44] McCool, JI., "Comparison of Models for the Contact of Rough Surfaces", Wear 1986, 107:37-60.

[45] Sayles, R.S. and Thomas, T.R., "Thermal Conductance of a Rough Elastic Contact", Appl. Energy, 1976, 2:249-67.

[46] Longuet-Higgins, M.S., "The Statistical Analysis of a Random, Moving Surface", Philos. Trans. Roy. Soc., A-Math Phys Eng Sci., 1957, 249:321-387.

[47] Bush, A.W., Gibson, R.D. and Thomas, T.R., "The Elastic Contact of a Rough Surface", Wear, 1975, 35:87-111.

[48] Habchi, W., Vergne, P., Bair, S., Andersson, O., Eyheramendy, D. and MoralesEspejel, G.E., "Influence of pressure and temperature dependence of thermal properties of a lubricant on the behaviour of circular TEHD contacts", Tribol. Int., 2010, 43:1842-1850.

\section{Acknowledgments}

The authors would like to express their gratitude to Lubrizol Ltd. for sponsorhip of this research. Special thanks are due to Dr. Farrukh Qureshi (The Lubrizol Corporation, Wickliffe, OH) for providing the high pressure viscosity data, to Dr. Eugene Pashkovski (The Lubrizol Corporation, Wickliffe, $\mathrm{OH}$ ) for providing the high shear viscosity data and to Dr. Sandeep Vijayakar (Advanced Numerical Solutions LLC, Hilliard, OH) for his kind permission to use the TCA software CALYX. 
Tribology International (Accepted version)

\section{Nomenclature}

a

$\mathrm{A}_{1}$

$A_{\text {asp }}$

$a_{c}$

$\mathrm{A}_{\mathrm{EHL}}$

$\mathrm{A}_{\mathrm{f}}$

$a_{h}$

$\mathrm{a}_{\mathrm{TTS}}$

b

$b_{c}$

C

$\mathrm{c}_{\mathrm{a}}$

$\mathrm{c}_{\mathrm{t} 1}, \mathrm{c}_{\mathrm{t} 2}$

E

e

$E^{\prime}$

$\mathrm{e}_{0}$

$\mathrm{e}_{\mathrm{ci}}, \mathrm{e}_{\mathrm{si}}$

F

f

$F_{2}, F_{5 / 2}$

$\mathrm{F}_{\mathrm{b}}$

$f_{r}$

$\mathrm{F}_{\mathrm{fr}}^{\mathrm{k}}$

$\mathrm{F}_{\mathrm{v}}$

g

G

$\mathrm{h}_{\text {cen }}$

ascent angle of the vehicle (rad)

Vogel’s temperature - viscosity parameter (K)

total area of asperity contact $\left(\mathrm{m}^{2}\right)$

length of the semi-major axis of the contact ellipse (m)

total area of EHD lubrication $\left(\mathrm{m}^{2}\right)$

frontal area of the vehicle $\left(\mathrm{m}^{2}\right)$

heat partitioning coefficient (-)

TTS shifting coefficient (-)

half backlash length (m)

length of the semi-minor axis of the contact ellipse (m)

gear mesh damping coefficient $(\mathrm{Ns} / \mathrm{m})$

coefficient of aerodynamic drag of the vehicle $(-)$

pinion shaft and ring gear shaft torsional damping coefficient (Nms/rad)

Young's modulus of elasticity of the gear pair $(\mathrm{Pa})$

static transmission error $(\mathrm{m})$

reduced Young's modulus of the gear pair teeth $(\mathrm{Pa})$

constant term in the static transmission error $(\mathrm{m})$

$\mathrm{i}^{\text {th }}$ cosine and sine terms of the static transmission error $(\mathrm{m})$

non-Newtonian rheological function (-)

backlash function (m)

statistical functions for the Greenwood - Tripp model (-)

boundary friction $(\mathrm{N})$

coefficient of rolling resistance between the tyre and the road (-)

total flank friction acting on the $\mathrm{k}^{\text {th }}$ flank pair (N)

viscous friction $(\mathrm{N})$

gravitational acceleration $\left(\mathrm{m} / \mathrm{s}^{2}\right)$

dimensionless material parameter (-)

central film thickness of the EHD conjunction (m) 
$\mathrm{I}_{\mathrm{i}} \quad$ mass moment of inertia $\left(\mathrm{kgm}^{2}\right)$

In $\quad$ RMS of the percent conjunctional inefficiency for 50 meshing cycles (-)

$\overline{\mathrm{k}} \quad$ approximation of the elliptical integral of the Hertzian contact theory (-)

$\mathrm{k}_{\mathrm{f}} \quad$ thermal conductivity of the lubricant $(\mathrm{W} / \mathrm{mK})$

$\mathrm{k}_{\mathrm{m}} \quad$ meshing stiffness $(\mathrm{N} / \mathrm{m})$

$\mathrm{k}_{\mathrm{m} 0} \quad$ constant term of the meshing stiffness $(\mathrm{N} / \mathrm{m})$

$\mathrm{k}_{\mathrm{mci}}, \mathrm{k}_{\mathrm{msi}} \quad \mathrm{i}^{\text {th }}$ cosine and sine terms of the meshing stiffness $(\mathrm{N} / \mathrm{m})$

$\mathrm{k}_{\mathrm{s}} \quad$ thermal conductivity of the mating flank surfaces $(\mathrm{W} / \mathrm{mK})$

$\mathrm{k}_{\mathrm{t} 1}, \mathrm{k}_{\mathrm{t} 2} \quad$ torsional stiffness of the pinion and ring gear shafts $(\mathrm{Nm} / \mathrm{rad})$

$l_{i} \quad$ active length of the footprint along the sliding direction on the $i^{\text {th }}$ surface $(m)$

$\mathrm{m}_{\mathrm{k}} \quad \mathrm{k}^{\text {th }}$ spectral moment of the surface roughness height distribution

$\mathrm{m}_{\mathrm{ka}}^{\mathrm{i}} \quad \mathrm{k}^{\text {th }}$ spectral moment of the surface roughness height distribution along the axial direction of the tooth for the $\mathrm{i}^{\text {th }}$ member of the gear pair

$\mathrm{m}_{\mathrm{ke}}^{\mathrm{i}} \quad \mathrm{k}^{\text {th }}$ equivalent isotropic spectral moment of the tooth surface of the $\mathrm{i}^{\text {th }}$ member of the gear pair

$\mathrm{m}_{\mathrm{kr}}^{\mathrm{i}} \quad \mathrm{k}^{\text {th }}$ spectral moment of the surface roughness height distribution along the radial direction of the tooth for the $\mathrm{i}^{\text {th }}$ member of the gear pair

$\mathrm{m}_{\mathrm{k}, \mathrm{ce}} \quad$ equivalent composite spectral moment of the composite interface between the teeth surfaces

$\mathrm{m}_{\mathrm{v}} \quad$ mass of the vehicle $(\mathrm{kg})$

$\mathrm{N}_{\mathrm{g}} \quad$ number of ring gear teeth (-)

$\mathrm{N}_{\mathrm{p}} \quad$ number of pinion teeth (-)

$\mathrm{p} \quad$ local Hertzian contact pressure $(\mathrm{Pa})$

$\mathrm{p}_{\mathrm{atm}} \quad$ atmospheric pressure $(\mathrm{Pa})$

$\mathrm{p}_{\max } \quad$ maximum Hertzian contact pressure $(\mathrm{Pa})$

$\dot{\mathrm{q}} \quad$ heat rate generation at the centre of the EHD conjunction (W)

$\mathrm{R}_{\mathrm{cf}} \quad$ conductive thermal resistance through the EHD film (K/W)

$\mathrm{R}_{\mathrm{e}} \quad$ effective contact radius of curvature along the direction of entraining motion (m)

$\mathrm{R}_{\mathrm{fi}} \quad$ conductive thermal resistance for the moving heat source on the $\mathrm{i}^{\text {th }}$ surface (K/W) 
$\mathrm{r}_{\mathrm{fr}, \mathrm{i}} \quad$ lever arm of the friction force about the axis of rotation of the $\mathrm{i}^{\text {th }}$ member (m)

$\mathrm{R}_{\mathrm{g}} \quad$ contact radius of the ring gear $(\mathrm{m})$

$\mathrm{R}_{\mathrm{g} 0} \quad$ constant term of the contact radius of the ring gear (m)

$\mathrm{R}_{\mathrm{gci}}, \mathrm{R}_{\mathrm{gsi}} \quad \mathrm{i}^{\text {th }}$ cosine and sine terms of the contact radius of the ring gear $(\mathrm{m})$

$\mathrm{R}_{\mathrm{p}} \quad$ contact radius of the pinion (m)

$\mathrm{R}_{\mathrm{p} 0} \quad$ constant term of the contact radius of the pinion (m)

$\mathrm{R}_{\mathrm{pci}}, \mathrm{R}_{\mathrm{psi}} \quad \mathrm{i}^{\text {th }}$ cosine and sine terms of the contact radius of the pinion $(\mathrm{m})$

$\mathrm{R}_{\mathrm{S}} \quad$ effective contact radius of curvature along the side leakage direction ( $\mathrm{m}$ )

$\mathrm{r}_{\mathrm{w}} \quad$ radius of the wheel of the vehicle $(\mathrm{m})$

$\mathrm{R}_{\mathrm{zx}}, \mathrm{R}_{\mathrm{zy}} \quad$ contact radius of curvature along the directions of entraining motion and side leakage $(\mathrm{m})$

t time (s)

$\mathrm{T}_{0 \text {,ref }} \quad$ reference temperature used in the Vogel temperature-viscosity equation (K)

$\mathrm{T}_{\mathrm{b}} \quad$ temperature of the oil bath (sump) (K)

$\overline{\mathrm{T}}_{\mathrm{c}} \quad$ average temperature at the centre of the EHD conjunction (K)

$\mathrm{T}_{\mathrm{fr}, \mathrm{g}} \quad$ total frictional torque acting on the ring gear $(\mathrm{Nm})$

$\mathrm{T}_{\mathrm{fr}, \mathrm{i}}^{\mathrm{k}} \quad$ frictional torque acting on the $\mathrm{i}^{\text {th }}$ member of the gear pair due to the friction force on the $\mathrm{k}^{\text {th }}$ flank $(\mathrm{Nm})$

$\mathrm{T}_{\mathrm{fr}, \mathrm{p}} \quad$ total frictional torque acting on the pinion (Nm)

$\mathrm{T}_{\mathrm{in}} \quad$ temperature of the lubricant at the inlet of the EHD conjunction (K)

$\mathrm{T}_{\text {ref }} \quad$ reference temperature used in the high shear viscosity measurements (K)

$\mathrm{T}_{\mathrm{s}} \quad$ input torque at the pinion shaft $(\mathrm{Nm})$

$\mathrm{T}_{\mathrm{w}} \quad$ resistive torque at the ring gear shaft $(\mathrm{Nm})$

U lubricant entraining velocity $(\mathrm{m} / \mathrm{s})$

$\mathrm{U}_{\mathrm{e}} \quad$ dimensionless speed parameter $(-)$

$\mathrm{U}_{\mathrm{eff}} \quad$ lubricant effective velocity used in Chittenden - Dowson equation ( $\left.\mathrm{m} / \mathrm{s}\right)$

$\mathrm{u}_{\mathrm{s}, \mathrm{i}} \quad$ surface velocity along the direction of entraining motion of the $\mathrm{i}^{\text {th }}$ member of the gear pair $(\mathrm{m} / \mathrm{s})$ 


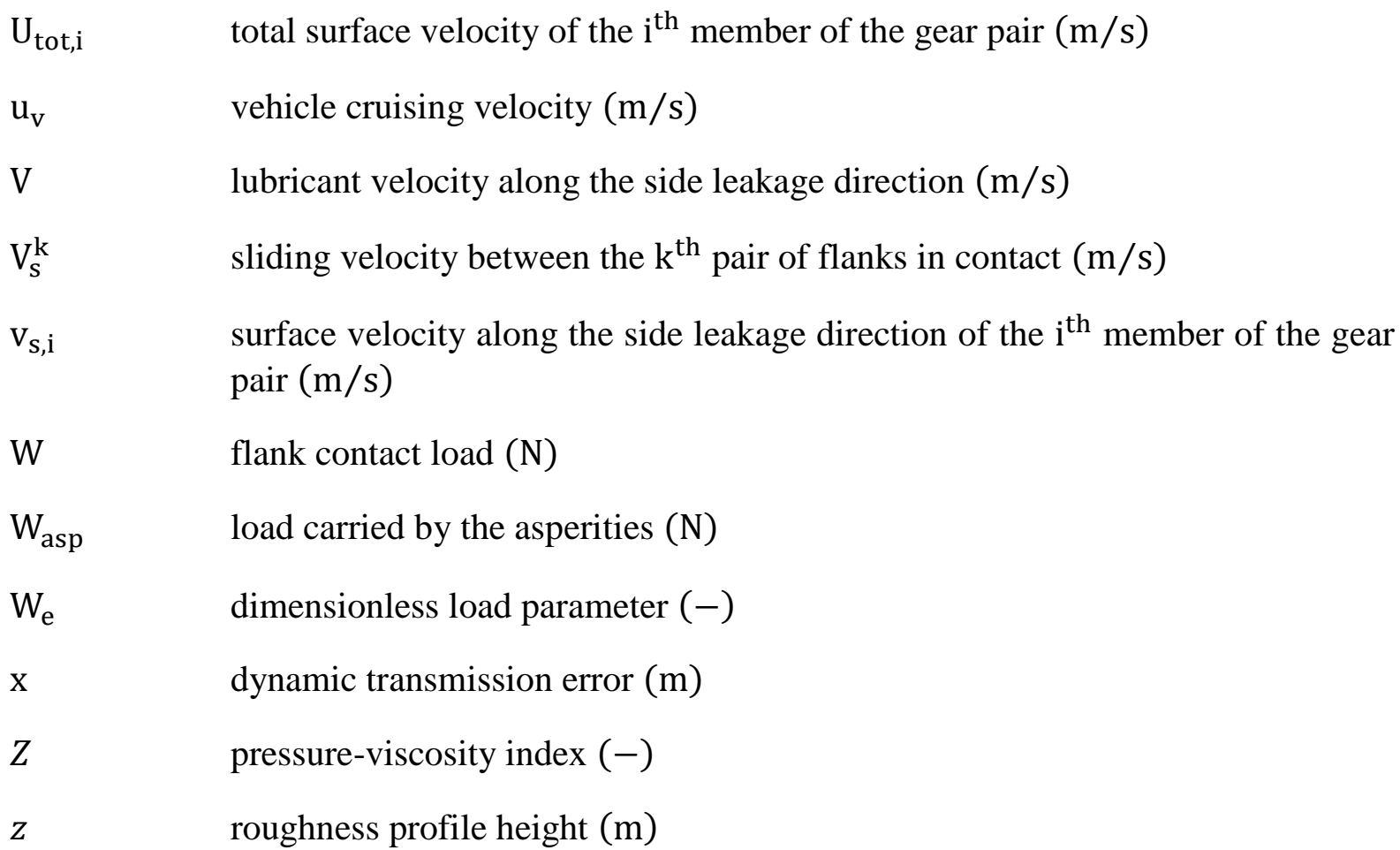

\section{Greek symbols}

$\alpha^{*} \quad$ reciprocal asymptotic iso-viscous pressure-viscosity coefficient of the lubricant $\left(\mathrm{Pa}^{-1}\right)$

$\alpha_{H N} \quad$ Havriliak-Negami coefficient (-)

$\alpha_{R} \quad$ Roelands' pressure-viscosity coefficient $\left(\mathrm{Pa}^{-1}\right)$

$\beta_{G} \quad$ average radius of curvature of the asperity summits $(m)$

$\beta_{H N} \quad$ Havriliak-Negami coefficient (-)

$\dot{\gamma} \quad$ lubricant shear rate at the centre of the conjunction $\left(s^{-1}\right)$

$\gamma_{L} \quad$ limiting shear stress - pressure proportionality coefficient (-)

$\left(\Delta T_{f}\right)_{a v} \quad$ average flash temperature rise $(K)$

$\left(\Delta T_{o i l}\right)_{a v} \quad$ average temperature rise due to the shear heating of the lubricant $(\mathrm{K})$

$\bar{\varepsilon}$ approximation of the elliptical integral of the Hertzian contact theory (-)

$\eta \quad$ lubricant dynamic viscosity (Pa. s)

$\eta_{0} \quad$ dynamic viscosity of the lubricant at ambient pressure (Pa.s)

$\eta_{0, \text { ref }} \quad$ dynamic viscosity of the lubricant at the reference temperature (Pa.s)

$\eta_{\mathrm{G}} \quad$ density of the asperities per unit area $\left(\mathrm{m}^{-2}\right)$ 
$\theta$

$\theta_{\mathrm{i}}$

$\lambda$

$\lambda_{\mathrm{s}}$

$v$

$\rho$

$\rho_{\text {air }}$

$\sigma_{\mathrm{G}}$

S

$\bar{\tau}$

$\tau_{0}$

$\tau_{\mathrm{L}}$

$\tau_{\mathrm{L}, 0}$

$\varphi_{\mathrm{i}}$

$\chi_{s, i}$

angle of the lubricant flow with respect to the semi-minor axes of the footprint (rad)

angle of the total surface velocity vector of the surface of the $i^{\text {th }}$ member of the gear pair with respect to the semi-minor axes of the footprint (rad)

relaxation time of the polymer blended in the lubricant (s)

Stribeck parameter, $\lambda_{\mathrm{s}}=\mathrm{h}_{\mathrm{cen}} / \sigma_{\mathrm{G}}(-)$

Poisson's ratio of the gear teeth material (-)

density of the lubricant $\left(\mathrm{kg} / \mathrm{m}^{3}\right)$

density of the air $\left(\mathrm{kg} / \mathrm{m}^{3}\right)$

composite RMS surface roughness between the teeth (m)

pressure coefficient of boundary shear strength for direct asperity interactions between steel surfaces $(-)$

local viscous shear stress of the lubricant $(\mathrm{Pa})$

average viscous shear stress of the lubricant at the centre of the EHD conjunction $(\mathrm{Pa})$

shear strength of the boundary tribofilm $(\mathrm{Pa})$

limiting shear stress of the bulk lubricant $(\mathrm{Pa})$

limiting shear stress of the bulk lubricant at zero pressure $(\mathrm{Pa})$

angle of rotation of the members of the system (rad)

thermal diffusivity of the tooth surface belonging to the $\mathrm{i}^{\text {th }}$ member of the gear pair $\left(\chi_{s, i}=k_{s} / \rho_{s} C_{p, s}\right)\left(m^{2} / s\right)$

\section{Subscripts}

av

i

g

G

$\mathrm{p}$

$\mathrm{S}$

$\mathrm{w}$ average

gear

ring gear

Greenwood - Tripp parameter

pinion

pinion shaft

ring gear shaft 
Tribology International (Accepted version)

\section{Abbreviations}

EHD Elastohydrodynamics

DoF Degrees of Freedom

DTE Dynamic Transmission Error

HV Havriliak-Negami

MTM Mini Traction Machine

PAO Polyalphaolefin

RMS Root Mean Square

STE Static Transmission Error

TTS Time Temperature Superposition

TCA Tooth Contact Analysis

VM Viscosity Modifier(s) 
Tribology International (Accepted version)

Appendix: Flowchart of the calculation procedure

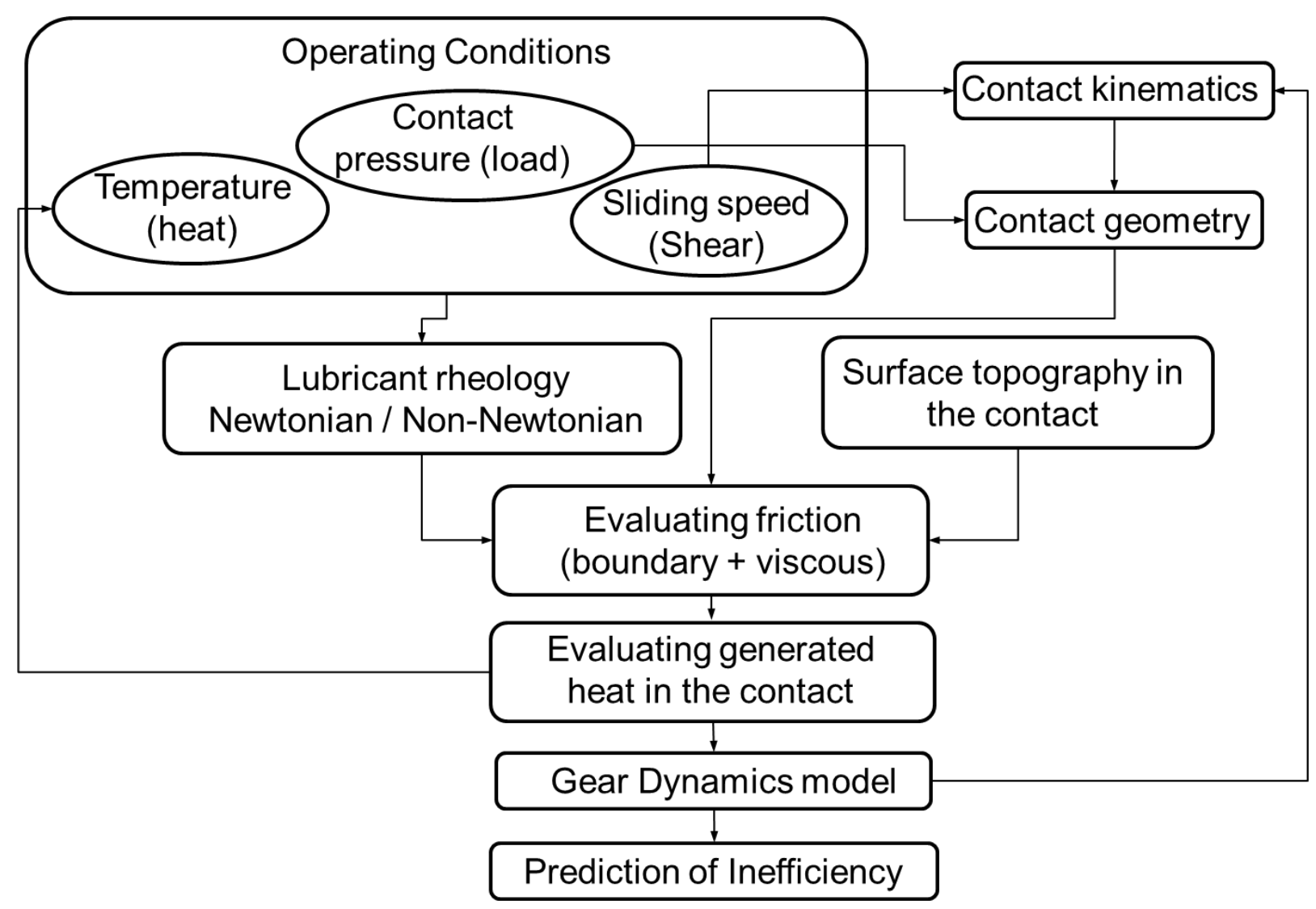

